\title{
A Loyal Base: \\ Support for Authoritarian Regimes in Times of Crisis
}

\author{
Anja Neundorf $^{a}$, Aykut Öztürk ${ }^{a}$, Ksenia Northmore-Ball $^{b}$, Katerina Tertytchnaya $^{c}$ \\ and Johannes Gerschewski ${ }^{d}$ \\ ${ }^{a}$ University of Glasgow; ${ }^{b}$ Queen Mary, London; ${ }^{c}$ University College London; ${ }^{d}$ Wissenschaftzentrum Berlin
}

June 2022 (Version 3)

\begin{abstract}
Does citizen support for the norms and principles of non-democratic regimes help stabilize authoritarian rule? While a large literature recognizes that authoritarian regimes depend on popular support to lower the costs of staying in power, existing research mainly views mass support for non-democratic regimes as instrumental, fuelled by performance. We know relatively little about the political effects of normative support and its relationship with instrumental forms of support. Using novel experimental evidence from original online surveys fielded in Turkey and observational data, we find high levels of normative support for the political system. We also find that, in the Turkish case, normative and instrumental forms of support are wrapped up together and that they condition the electoral consequences of poor economic performance. These findings, which revisit the importance of normative support for regime resilience, have implications for research on mass opinion and defection cascades in electoral autocracies.
\end{abstract}

Keywords: Authoritarian regimes; public opinion; economic crises; survey experiments; Turkey. 


\section{Introduction}

Electoral autocracies, regimes that combine authoritarian practices with multi-party elections, are the dominant form of non-democracy today. ${ }^{1}$ With the costs of brutal force and coercion rising, contemporary authoritarians find it increasingly important to persuade the masses that they are competent and need popular support in order to lower the costs of staying in power and win elections (Guriev and Treisman 2020). Managing public opinion is a key challenge confronting contemporary illiberal incumbents (e.g. Hale 2015). A decline in popular support for authoritarian incumbents' performance in office as well as a decline in trust in their regimes represent a key source of regime vulnerability and are a chief predictor of unrest (Geddes and Zaller 1989; Magaloni 2006; Mauk 2020; Guriev and Treisman 2020; Rosenfeld 2020).

Research in authoritarian politics has predominantly viewed citizen support for authoritarian rule as instrumental in nature - fuelled by the provision of economic growth and public goods. This scholarship, which can be summarized by the "authoritarian social contract" thesis (Desai et al. 2009), has generated the expectation that illiberal regimes should be sustained when the economy grows and lose support when performance deteriorates. According to Geddes (1999), while economic growth enables illiberal incumbents to exchange patronage and public goods for loyalty and support, economic downturns make material resources difficult to mobilize. At the same time, while studies recognize the importance of nationalism and religion for fuelling normative support for authoritarian rule (e.g. Kuzio 2016; Gill 2019; Dukalskis and Lee 2020; Koesel et al. 2020), our understanding of the consequences of normative support, i.e. citizens' principled support for the norms, values, and principles of authoritarian regimes, remain limited. In contemporary electoral autocracies are citizen views and principles congruent with those of the regime? And, can support for the norms and principles of non-democratic regimes help stabilize authoritarian rule, even when performance is poor?

Building on research regarding the origins and consequences of instrumental and normative support, developed mostly with reference to democratic regimes, (Easton 1965a; Dalton 1999; Claassen and Magalhães 2021), we propose that scholarly understanding of support for authoritarian rule as

\footnotetext{
${ }^{1}$ Electoral authoritarian regimes have become the most common regime type in the world during the post-Cold War period, both in terms of the number of countries and in terms of the size of overall population. According to Hellmeier et al. (2021: 1057)'s classification, 62 countries, corresponding to $43 \%$ of world population, were ruled by electoral authoritarian regimes in 2020 .
} 
Figure 1: Erdogan's approval and Turkish Lira exchange rate over time

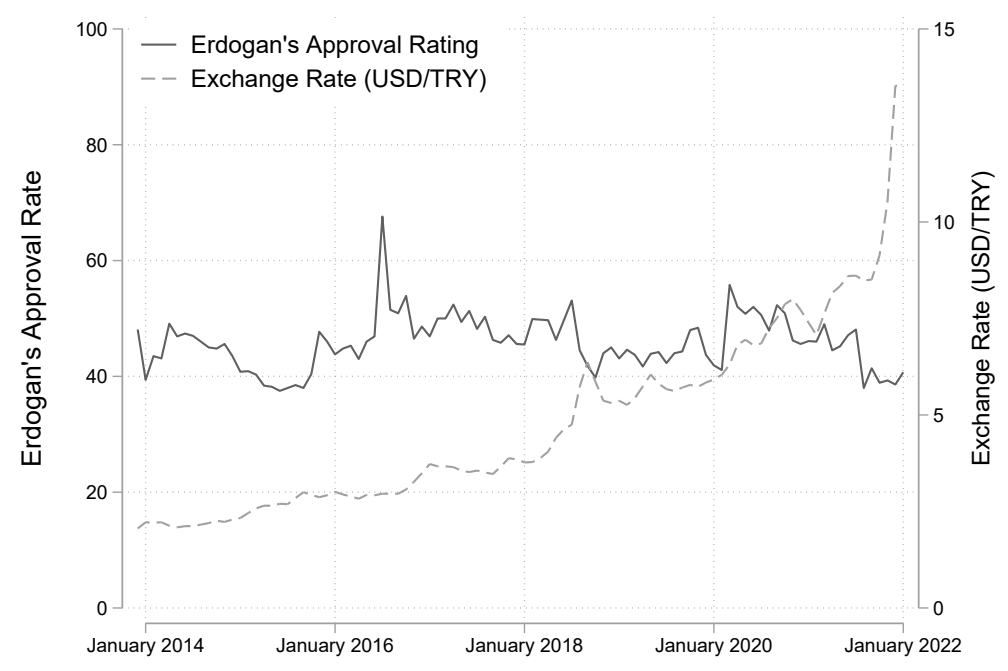

Source: This figure relies on monthly survey data from Metropoll's "Turkey's Pulse" surveys, one of Turkey's most reputable public opinion firms. Exchange rate data is the monthly average price of buying USD, and it is received from the Central Bank of the Republic of Turkey (TCMB).

simply instrumental in nature, i.e. as exclusively driven by performance, is perhaps narrow in scope. Like citizens in developed democracies, we assume that citizens in electoral autocracies may support the norms and principles of the political system in place. In a similar vein, we anticipate that normative support for authoritarian rule, often resilient to fluctuations in policy outputs, could mitigate the electoral consequences of poor performance.

The expectation that congruence with regime norms and values may contribute to authoritarian resilience is motivated by the observation that, despite protracted periods of poor performance, mass support for illiberal incumbents often remains resilient. For example, despite economic contraction throughout 2014-16, Russia's Vladimir Putin enjoyed approval ratings as high as $89 \%$. Turkey's Recep Erdogan has also continued to enjoy high approval, even as Turkey's growth declined and youth unemployment and inflation increased. Protracted economic decline coincided, paradoxically, with sustained support for the ruling regime, as shown in Figure 1. Despite a dramatic decline in the valuation of the Turkish Lira to the US Dollar, which caused a severe economic crisis, the approval rating of Erdogan remained unchanged between 40-50\%. A reservoir of political support, perhaps in the form of normative convictions, could help sustain citizen loyalty and incumbent approval, contributing to the resilience of authoritarian regimes.

We empirically test expectations regarding the consequences of normative support for authoritar- 
ian rule using novel experimental data from two well powered online surveys in Turkey. Turkey, an electoral autocracy with strong personalist rule, provides a helpful setting for empirically testing expectations (Cleary and Öztürk 2020; Yilmaz and Bashirov 2018). We begin by building on prior research in order to select survey items that tap into each concept of interest, normative and instrumental support (e.g. Dalton 1999; Norris 1999). In addition to relying on indicators previously used in cross-national research on political system support, we design and field new survey items welltailored to the Turkish context. The ability to rely on survey measures specific to the local context is a distinct advantage of our approach. Using two experimental studies, we study the effect of economic downturns on normative and instrumental forms of support and their ability to moderate the electoral consequences of poor performance. Finally, we probe the external validity of experimental findings using a nationally representative survey of voting-age respondents conducted face-to-face in 2018.

To preview our findings, we find that authoritarian regimes may enjoy both normative and instrumental forms of support, largely concentrated among government voters. We also find that, for the Erdogan regime, normative and instrumental forms of support are wrapped up together. Despite the conceptual distinction between normative and instrumental forms of political system support (e.g. Norris 1999), empirical evidence suggests that, in contemporary Turkey, the two forms of support largely overlap. It is possible that in authoritarian settings, normative attachment has instrumental foundations, just like instrumental support is colored by affective attachment. For example, voters who support the authorities for instrumental reasons might become more receptive to the regime's propaganda and develop normative support for regime values and principles as well. What is more, drawing on experimental data, we show that political support may condition the electoral consequences of poor economic performance. In an experimental setting, regime supporters who exhibit the highest levels of normative or instrumental support are unaffected by information about economic decline. Confronted with information about poor economic performance, these individuals, who account for as much as $45 \%$ of the AKP's supporters, are more likely to remain loyal to the ruling regime party and less likely to defect to the opposition than others. Indeed, across authoritarian regimes, the distribution of political support in the population may help shape the political consequences of poor performance. The larger the share of voters who espouse regime norms and principles or who approve of the regime's performance prior to downturns, the most resilient we may expect authoritarian systems to be.

Our work joins several studies in building on Easton's political system support framework (Dalton 
1999; Norris 1999; Klingemann and Fuchs 1995) and, in line with Mauk (2020), extends that agenda to non-democracies. While we are not the first to emphasize the importance of normative support for authoritarian rule (see, for example Geddes and Zaller 1989), our study adds to existing scholarship in several ways. To begin with, we draw renewed attention to the importance of popular support for the values and principles of non-democratic regimes, beyond the role of religion and nationalism, and highlight their importance in preventing voter defections from the dominant party (e.g. Hale and Colton 2017). To empirically test hypotheses we could rely on tailored survey indicators that capture the principles, norms and structures of contemporary electoral autocracies in general and those of the Turkish regime in particular. Our experimental approach helps alleviate threats to inference that are common with observational data typically used in studies of authoritarian regime support. Finally, we explicitly test the resilience of support in times of crisis. Findings have broader implications for our understanding of authoritarian stability and democratic transitions. Evidence that support for the political system, such as identification with the political community and with regime norms and principles, helps prevent voter defections in the context of poor performance suggests another avenue that could hinder electoral punishment in authoritarian settings (e.g. Hale and Colton 2017; Beazer and Reuter 2019).

\section{Forms of Support and Voting Behavior in Authoritarian Settings}

\subsection{Instrumental and Normative Forms of Support}

Authoritarian politics scholarship agrees that managing public opinion is a key challenge confronting electoral authoritarian regimes (Hale 2015) and shows that several authoritarian regimes are genuinely popular with citizens (Guriev and Treisman 2020; Matovski 2021). Novel survey techniques, including item count methods, have enabled scholars to show that, in certain contexts and periods, the popularity of authoritarian incumbents does indeed reflect public opinion. In a series of experiments that took place in Russia in 2015, for example, Tim Frye and his co-authors documented that Putin's approval accurately reflects the views of ordinary Russians (Frye et al. 2017).

Political science research has for decades understood citizen support for authoritarian rule as primarily instrumental in nature (Magaloni 2006). Instrumental support hinges on a quid-pro-quo relationship in which the citizens support the political system as long as it delivers. According to Dalton (1999), instrumental support "involves a judgment about the performance, or appropriateness of an 
object". While incumbents are able to remain securely in power when they deliver, their tenure is challenged when performance deteriorates. This line of research generates the expectation that when the system fails to deliver, or when its ability to meet citizen demands wavers, citizens update their evaluations of the regime downward and withdraw their support.

Previous research on public opinion in electoral authoritarian regimes shows evidence of instrumental forms of support such as approval with economic performance and leadership (Treisman 2014) and more generally confidence in regime institutions (Mauk 2020). The more limited research on popular support for various understandings of democracy that do not conform to standard conceptualisation of liberal democracy (Fuchs 2007; Schedler and Sarsfield 2007; Booth et al. 2009; Hale 2011; Carlin and Singer 2011; Shin 2021), and studies of mass support for authoritarian rule (Mauk 2020; Rose and Mishler 1996) also suggests the potential for normative support for authoritarian systems. These studies, as well as research emphasizing the importance of religion and nationalism for generating sustained support for authoritarian rule (e.g. Gill 2019; Kuzio 2016; Dukalskis and Lee 2020), form the starting point of our work.

Also referred to as "diffuse" (Easton 1965b) and later as "affective" (Dalton 1999), normative support for the political system represents adherence to a particular set of values that the political system embodies. Normative support, which aligns with what the system stands for and refers to normative congruence between the ruler and the ruled, is more resilient to short-term fluctuations in performance. For example, patriotic feelings of attachment to the nation can help counteract the negative effects of poor performance and bolster loyalty to the dominant party (Koesel et al. 2020). Citizens' democratic orientations can also help facilitate democratization by encouraging citizen compliance even with difficult policy decisions (Norris 2011: Ch. 11). As shown elsewhere, strong partisan attachments can also dampen economic voting, the extent to which citizens reward or punish incumbents for changes to their pocketbook and the economy (Evans and Pickup 2010; Gerber and Huber 2010).

Our concept of normative support focuses on the congruence between the regime and its citizens in terms of the political principles, institutions and key authorities that represent the political system. We expect that normative supporters display a sense of loyalty and commitment to the system that can resist setbacks. As Easton (1965b) reminds us, resilient normative support may function as a bulwark against short-term fluctuations in performance. Indeed, according to Easton (1965b: 273), 
normative support represents a "reservoir of favorable attitudes or good will that helps members accept or tolerate outputs to which they are opposed to".

\subsection{Resilience of Political Support and Voter Loyalty}

Drawing on research regarding the origins and consequences of political system support (e.g. Easton 1965a), we formulate theoretical expectations on two aspects. First, we explore the resilience of forms of political support in times of poor performance. Second, we study in more depth the relationship between these forms of support and electoral behavior. We start from the assumption that political support is distributed heterogeneously among voter groups. We introduce a broad distinction between government and non-government voters and set forth that government voters should have higher shares of both normative and instrumental support than non-governmental voters. We also ask whether political support inspires loyalty among pro-government voters, dampening the probability that they would defect from the dominant party in times of crisis.

In a first step, we compare the extent to which instrumental and normative forms of support respond to deteriorating regime performance, e.g. during an economic crisis. Easton (1975: 444) explicitly notes that the different forms of support do not move together in response to poor performance. The genesis of the different forms of support, normative and instrumental, differs: normative support arises out of childhood and adult socialization, or out of experience over a very long period of time. Attachments to various elements of the political system the national community, namely a sense of national identity and commitments to certain political values are largely shaped through parental influences as well as early life socialization processes like education and formative events. Instrumental support, on the other hand, is fundamentally evaluative, tied to real-time fluctuations in performance. As a result, existing research generates the expectation that instrumental support is more responsive to policy outputs than normative support. Yet, no tests exist that explore the comparative resilience of normative and instrumental forms of support in non-democratic regimes. As such, our first hypothesis anticipates instrumental forms of support to be more responsive to economic performance than normative forms of support (Hypothesis 1).

Next, we arrive at what lies at the heart of Easton's theory of system support and a key question of debates regarding the 'crisis of democracy debates' in the 1960s and 1970s: the puzzle of how political systems can survive periods of poor performance. These debates were informed by the 
understanding that political systems cannot meet all popular demands and that they will experience performance shocks hindering their ability to deliver from time to time. Easton (1965a) proposes that normative forms of support act as a generalized reservoir of support and help mitigate the negative effects of poor policy performance. Building on this discussion, in our work we explicitly disentangle the attitudinal dimension of support from its behavioral consequences. We specifically ask to what extent normative and instrumental forms of support prevent ruling party voters from defecting at the polls when performance is poor. As studies of economic voting show, when performance is poor, electoral support for incumbents in democracies (Lewis-Beck and Stegmaier 2007) and non-democracies alike declines (e.g. Rosenfeld 2020; Beazer and Reuter 2019; Treisman 2011). Understanding whether, and to what extent, support for the political system can cushion the electoral consequences of poor performance is therefore an important task for studies of economic voting and authoritarian politics more broadly.

Altogether, while we expect poor performance to reduce electoral support for the dominant party (Hypothesis 2), we also anticipate that this effect may be conditional on individuals' levels of system support. Voters with high levels of normative and instrumental support may be less likely to defect from the dominant party, and more likely to remain loyal to it. Indeed, as existing research reminds us, loyalty, a subset of support (Gerschewski 2018), becomes most obvious in times of crisis. ${ }^{2}$ As such, we expect instrumental and normative system support to condition the effect of poor performance on voter defections. The higher dominant party voters' levels of system support, the lower the probability of them defecting (Hypothesis 3a).

Finally, in line with Easton (1965a), we expect that the form of support matters. We set forth that normative support conditions the effect of poor performance more strongly than instrumental support does (Hypothesis 3b). As argued above, normative support serves as a generalized reservoir of goodwill to the regime that is better equipped to overcome times of crises. It can be assumed that high levels of normative support are better suited to absorb and cushion negative behavioral consequences in times of bad performance. In contrast, instrumental support is based on a constant updating of a quid-pro-quo relationship between granting of support and the regime delivering. In times of bad performance, instrumental support is less able to cushion electoral consequences.

To summarize our expectations, we anticipate poor performance to reduce instrumental, but not

\footnotetext{
${ }^{2}$ Already Hirschman (1970) has argued that loyalty - together with the more analyzed options of exit and voice - should be seen as the title indicates as a "response to a decline in firms, organizations, and states".
} 
normative forms of support. We also expect that, while poor performance may decrease electoral support for the dominant party, this effect could be conditional on political support. Finally, we posit that normative support may moderate the electoral consequences of poor performance more strongly than instrumental support does.

\section{Research Design}

In this study we aim to test the impact of an economic crisis on the electoral support of the governing parties of an electoral autocracy, which we conceptualize as an intended behavioral outcome. We expect that the impact of the crisis is conditioned by an individual's level of support for the regime, which is conceptualized as attitudinal support or a preference. We thereby acknowledge that these preferences of support for the regime and the behavioral support for the governing parties are somewhat endogenous. Voting for these parties can also impact preferences due to cognitive dissonance whereas individuals' will bring their preferences in line with their behavior (Bølstad et al. 2013).

To tease out the hypothesized relationship between our concepts we rely on an experimental design, whereas we compare an experimental treatment group that gets primed on an economic crisis with a control group. To implement the experiment, we chose Turkey as a case study. In this section, we provide a rationale for our case selection as well as the details of our experimental design and measurements.

\subsection{Case Selection: Background to the Turkish Context}

We test our theoretical expectations using original public opinion data collected in Turkey. Turkey is a paradigmatic examples of electoral authoritarian regimes, in terms of both the origins and common practices of this regime type (Bermeo 2016; Hellmeier et al. 2021; Matovski 2021). Furthermore, despite a period of protracted economic crisis, experienced since the mid-2010s, support for the Turkish presidnet has remained high (see Figure 1). This makes Turkey a "deviant case" from the perspective of "authoritarian social contract" literature (Levy 2008).

Similar to other electoral autocracies, such as Russia, Venezuela, and India, authoritarianism in Turkey has emerged as a result of the gradual degeneration of electoral institutions under the rule of a personalistic authoritarian leader (Hellmeier et al. 2021; Lührmann et al. 2019; Svolik 2019: 
911). Recep Tayyip Erdogan and his Justice and Development Party (AKP) came to power through free and fair elections in 2002. Once in power, Erdogan skillfully took advantage of political and economic developments in the country to consolidate his personal power and to dismantle democratic institutions (Cleary and Öztürk 2020).

By 2022, the entire state apparatus in Turkey was largely under Erdogan's control. The constitutional referendum of 2017 has formalized Turkey's hyper-presidentialist institutional structure. While elections are still in place, they are neither free nor fair (Esen and Yardimci-Geyikçi 2020). Throughout this process of democratic breakdown, Erdogan kept his popularity among the majority of Turkish citizens, as reflected in opinion polls and elections. Since 2007, the AKP maintained a vote share of over 40\%. Erdogan won the presidential elections of 2014 and 2018 in the first round, each time receiving more than $50 \%$ of the national vote. Regular opinion polls by reliable survey companies (as seen on Figure 1) and other studies (e.g. Laebens and Öztürk 2021) also point to the fact that Erdogan and the AKP enjoy genuine political support.

Erdogan's and the AKP's popular support is particularly puzzling given Turkey's recent economic downturn, which started in 2013 but has much worse since 2018. Despite the protracted economic crisis, performance evaluations may still help explain the popularity of Erdogan. Erdogan benefited from the favorable international economic conditions of the early 2000s during his first two terms. Historically high growth rates and positive relations with neighbouring countries and international organisations, such as the EU, helped Erdogan build the image of a competent leader. As these successes have constantly been promoted by Erdogan's propaganda machine, the image of competency might still resonate with some voters. Furthermore, during the last decade, Erdogan and his government have been able to build general credibility based on foreign and security policies. Shifting the public's focus to these issue areas, with the help of the authoritarian media power, can help sustain instrumental support for the government (Aytaç 2021). At the same time, in the last decade, Erdogan and his government have invested in building normative foundations for the current political system. Erdogan explicitly distinguishes Turkey's new political system from the previous one, calling the new system as "New Turkey" (Aliriza 2018). Through his speeches, educational reforms, and the media power, he aims to instill norms, values, and affective attachments that legitimize his authority (Yilmaz 2018).

It is possible to define unique characteristics of the current authoritarian system in Turkey which 
we expect to translate into normative support among citizens. To begin with, Erdogan's "New Turkey" offers an alternative sense of community to the republican and secular nationalist identification of the previous political system in Turkey (Yabanci 2020: 105). This alternative identification is rooted in the imperial nostalgia for the Ottoman Empire, predominant among Turkish-Islamist ideological groups in Turkey (Yavuz 2020; Elçi 2021). Legitimation of authoritarian regime practices also holds an important place within the government discourse. Although Erdogan and his system still describe Turkey as an "advanced democracy," they also adopt a rhetoric that legitimizes the rule by a strong leader, limits on media freedom, and arrest of politicians from other parties. ${ }^{3}$

Finally, the personality cult around Erdogan has a central place in terms of the normative and affective foundations of the current political system in Turkey. Within the discourse of the regime, Erdogan is portrayed as a leader with extraordinary features and devotion to the nation. Occasionally, this personality cult results in the violation of the boundary between the religious and political domains, as Erdogan is referred as "a leader who gathers all of Allah's qualities in himself," and "the shadow of Allah on earth" (Yabanci 2020). This discourse resonates with Erdogan's voters as well, who use emotionally-laden concepts, such as love, affection, and loyalty when referring to him (Çelik and Balta 2020: 168).

\subsection{Data collection}

To empirically test our expectations, we ran two original online surveys in Turkey. Data collection was conducted between May 9 and 24, 2021. ${ }^{4}$ Respondents to our surveys were recruited through paid Facebook advertisements, which invited Facebook users to participate in "a survey on current issues in Turkey". We used twelve different advertisements, varying on the use of material incentives, advertisement text, and advertisement image. ${ }^{5}$ Facebook users who clicked on the advertisements

\footnotetext{
${ }^{3}$ For example, "the need for a strong presidency for political stability and effective governance" was the main argument the AKP and Erdogan used in the campaign period of 2017 constitutional referendum, which eventually turned Turkey's parliamentary system into a hyper-presidential system (Esen and Gümüşçü 2017). In the following 2018 presidential election, one of Erdogan's official slogans was "Great Turkey needs a strong leader."

${ }^{4}$ We received ethical approval and submitted a pre-analysis plan for the study before data collection commenced. The pre-analysis plan was submitted on May 7, 2021 can be accessed here: https://osf.io/ $\mathrm{kj} 8 \mathrm{zh} /$ ?view_only=5216778db97b40e18158b01440cb081d. Additional hypotheses that were registered and divergences from the pre-analysis plan are discussed and reported in Appendix 16. The study received ethical approval (number: 400200111) from the Ethics Committee of the XXX at the University of XXX on March 24, 2021 (information removed for anonymity).

${ }^{5}$ More information on our Facebook recruitment strategy can be found in the Appendix 2.
} 
were directed to a survey page hosted on Qualtrics. Before taking the survey, respondents were informed about the purpose of the study, their rights, and the length of the survey (about $10 \mathrm{~min}$ utes). In total, we recruited 6,111 respondents through Facebook advertisements, which is beyond the required sample size based on our power calculations. ${ }^{6}$

Although our sample was formed through an online opt-in recruitment process, we used Facebook targeting tools and material incentives to increase the extent to which the sample is representative of the Turkish population. The distribution of respondents in the sample closely follows the population distribution with respect to geographic regions, age categories, the proportion of non-college voters, and voting behavior. However, females and non-high school respondents are underrepresented. To correct these imbalances in our descriptive analyses, we created a post-stratification weight taking into account the distribution of the Turkish population according to cross-categories of sex, education, and geographical region based on 2020 official census data. Details of the original and weighted sample characteristics are presented in Table A.1 in Appendix 3.

\subsection{Measuring normative and instrumental support}

The chief advantage of fielding our own survey is the opportunity to design and field items that tap into all theoretical concepts of interest and in a manner that best reflects the specific national ethnoreligious and electoral authoritarian context of Turkey. In measuring political support, we aimed to cover the matrix of objects and forms of support as defined conceptually by Dalton (1999). We employed survey items commonly used to capture different types of support (e.g. policy evaluations) and newly designed questions that directly derive from the theoretical concepts introduced in earlier sections and previously used by scholars such as Dalton. The full battery of survey items used is listed in Appendix 4.

To measure normative support, we combine ten survey items. Firstly, we rely on two items on national and religious pride and a question that taps into the government's emphasis on a form of Turkish nationalism that primes the Ottoman past and Islam (Yavuz 2020). To capture normative

\footnotetext{
${ }^{6} 6,484$ survey responses were recorded on our Qualtrics page, 373 of whom shared the same IP address with at least one previous survey response. We dropped these observations to ensure that each completed questionnaire comes from a different respondent. This left us with 6,111 unique Facebook users, who remained engaged in the survey long enough to take part in the experiments and who had responses on all key variables. 2,043 of these Facebook users were directed to Survey 1 and 4,068 of them were directed to Survey 2. The analysis relies on this subset of respondents. Power calculations are available in Appendix 1.
} 
support for the regime principles we also designed new items that reflect the electoral authoritarian nature of the current Turkish regime along with characteristics of personalism and delegative democracy (Taş 2015; O’Donell 1994). As such, we include the question asking about support for strongman rule, commonly used in other electoral authoritarian contexts such as Russia (Hale 2011). This item captures one of the defining characteristics of electoral authoritarianism which is a strong executive leader, or caudillismo (O'Donell 1994). To further capture support for regime principles which in democratic contexts would include freedom, tolerance of minorities, and pluralism, we created indicators that tap into support for majoritarianism which only allows religious and nationalist parties to compete in elections (Karagiannis 2016) and limits free media (Waldman and Caliskan 2017).

We further designed four items that capture normative support for the AKP, the main ruling party, and Erdogan. The items were designed not to tap into any performance evaluation, but rather represent a more general commitment to the mission of the party and the leader. For example, we asked whether respondents agree that "those who fight against the AKP in fact fight against the Turkish nation and state" or that "Recep Tayyip Erdogan is an inspiring political leader".

In contrast, our six items that tap into instrumental support were aimed to capture a performance evaluation of various objects. Firstly, we asked a very general question whether "Turkey is a country that provides high quality life for its citizens". ${ }^{7}$ Further, we directly asked respondents to evaluate the success of Erdogan and the economic minister, as two key political figures, and to assess three key policy areas - the economy, the fight against poverty and internal security.

Responses to all survey items range on a scale from 1-5, with higher values denoting greater support or agreement with each of the statements provided. To construct the normative and instrumental support indexes used in the analysis, we calculate the average score for each list of items, and then multiply this value by 20 . Using $0-100$ scales allows us to interpret changes in percentage points. ${ }^{8}$

\footnotetext{
${ }^{7}$ As we discuss more extensively in Appendix 16.3, while the surveys also ask about trust in elections, the Presidential system, and the Directorate of Religious Affairs, these items are omitted from the analysis. Theoretically, it is unclear whether trust items should be assigned to normative or instrumental forms of support

${ }^{8}$ It is reasonable to ask whether respondents in Turkey feel free to answer questions honestly. The fact that opposition respondents clearly state their dissatisfaction with the political system suggests that they did not feel constrained to give only answers favorable to the regime (see Table 2). To study the extent of preference falsification in the survey we also fielded a series of list experiments, using three different survey items. The results and more details about the analysis are presented in Appendix 5. Altogether, evidence suggests that preference falsification is not significant among government voters, with the exception of certain items that tap into support for media bans and assessments of Erdogan as inspiring. In the survey experiments, we might anticipate preference falsifiers to be distributed equally between the treatment and control groups.
} 


\subsection{Experimental design}

To explore how economic performance impacts system support (Hypothesis 1), and the extent to which political system support moderates the electoral consequences of poor performance (Hypotheses 2 and 3), we designed a priming experiment that manipulated information about the state of the Turkish economy, a salient performance indicator. The experiment consisted of two experimental groups, control and treatment. Respondents were randomly assigned to each of them. Across the two surveys, we achieved good balance between the treatment and control groups in terms of pretreatment variables. ${ }^{9}$

The control group did not see any information about the economy, while we primed respondents in the treatment group on the on-going economic crisis in Turkey focusing in particular on the exchange rate. ${ }^{10}$ Our vignette read as follows:

"Turkey is dealing with an economic crisis for several years now. Since the beginning of 2020, the value of the dollar has increased from 6 TL (Turkish Liras) to 8.3 TL as the Turkish lira's value decreased around 25\%. As a result of these economic problems, the Turkish economy has dropped three places in the ranking of the world's biggest economies. Turkey's economic problems reveal themselves in the daily life too. Many citizens complain about the continuous increase in prices. Another issue is unemployment, which is especially common among the youth."

After reading the vignette, respondents in the treatment condition were asked: "What do you think is the biggest economic problem in Turkey"? Response options included the decline of the Turkish lire, unemployment, increases in the cost of living, or any other issue that respondents could report. The goal in this question was to strengthen the treatment and make respondents think further about Turkey's economic troubles. As we show in a manipulation check reported in Figure A.9 in Appendix

\footnotetext{
${ }^{9}$ Balance tests are shown separately, for all respondents, government and non-government voters, in Table A.5 in Appendix 6. We run most of the analysis on the latter sub-samples of respondents. As balance tests show, we only have one imbalance in the full sample of survey 1 , where urban respondents are over-represented in the treatment group. Furthermore, income is significant at the $10 \%$ level in the government voter sample in Survey 2. To account for these imbalances we include the respective control variables when analysing each of the respective samples - the full sample in Survey 1, and the sub-sample of government supporters in Survey 2.

${ }^{10}$ Between January 2012 and January 2022, the value of Turkish lira has decreased from 0.53 USD to 0.07 USD. It can be argued that this decrease has been the most visible and salient dimension of Turkey's protracted economic decline for Turkish voters, not only because it has far-reaching economic effects on the inflation in an open economy like Turkey, but also because it has been one of the few reliable economic indicators within Turkey's authoritarian context.
} 
14 , our treatment successfully shifted economic evalutations - those exposed to the vignette gave more negative evaluations. This is especially the case for government voters.

The priming experiment described here was included in both of the surveys we conducted online. ${ }^{11}$ In the first survey, the respondents were exposed to the economic treatment just before they answered questions about their instrumental and normative support for the regime. By comparing differences in support between the control and treatment groups, we can test whether information on economic performance has less of an effect on normative support than instrumental support (Hypothesis 1). In the second survey, the priming experiment was done after respondents answered the support questions. This set-up allows us to test the direct consequences of poor performance on electoral support ( Hypothesis 2), and whether political system support moderates these electoral consequences (Hypothesis 3).

To measure behavioral regime loyalty, we asked questions that measure electoral support posttreatment. A question asks how likely respondents are to vote for each of the following: (1) the AKP or the MHP, the two government parties; (2) the Nation Alliance (CHP and IYI), two of the opposition parties, (3) the HDP, another opposition party, ${ }^{12}$ and (4) not to vote at all. ${ }^{13}$ Respondents who voted for one of the government parties in 2018, the AKP or the MHP, were additionally asked about participation in different forms of pro-government mobilization by joining rallies, campaign contributions, or other forms of pro-government agitation. ${ }^{14}$ We create an index of these three items using the average score of responses to each question.

\footnotetext{
${ }^{11}$ In both surveys, respondents were asked a battery of standard demographic controls. They reported their age, gender, education, religiosity, domicile (urban/rural), political interest, partisanship, income, and retrospective economic evaluations. In both surveys, these questions were asked before the experiment. The retrospective economic evaluation was asked after the treatment as well. For a full list of questions used, please see Appendix 4.

12 We treated the HDP as a separate opposition party, as it is the main party representing Kurdish interests. Due to the ethnic polarization in Turkey, other opposition parties are careful to distance themselves from the HDP, and the HDP and the Nation Alliance do not form a uniform block of opposition.

13 The question is asked as follows: "How likely are you to vote for one of the parties listed below if the election is held in one week" ( $1=$ Not likely at all; 4 =undecided; $7=$ certainly $)$

${ }^{14}$ These questions read as follows: "How likely are you to do the following: (1) Joining an AKP's rally; (2) Encouraging friends and family to vote for the AKP; (3) Contributing to the AKP's election campaign." Responses to all items are measured on a 7-point scale (1=Not likely at all; 4 =undecided; $7=$ certainly).
} 


\section{Results}

We first descriptively explore the relationship between instrumental and normative forms of support and present general patterns in their distribution in the sample. Next, we experimentally test how responsive forms of support are to the economic crisis treatment (Hypothesis 1); how the treatment impacts respondents' vote intention and likelihood to mobilize in support of AKP (Hypothesis 2); and, finally, whether the electoral consequences of poor performance are conditional on political support (Hypothesis 3). Across the study, we treat vote intention and AKP mobilization, as indicators of behavioral support for the government. We conclude by replicating key findings leveraging evidence from nationally representative survey data. While random assignment to treatment is the key strength of the experimental design, observational data alleviate concerns about external validity.

\subsection{Descriptive analysis: Instrumental and normative system support}

We begin by exploring the relationship between the different items that tap into normative and instrumental forms of support. Findings suggest that, contrary to theoretical expectations (e.g. Easton 1965a; Dalton 1999), in the Turkish context, normative and instrumental support are wrapped up together. The overall correlation between the different items that tap into normative and instrumental support is very high, round $0.88 .{ }^{15}$ Exploratory factor analysis of the items used to measure normative and instrumental support, presented in Table 1 below, also suggests that normative and instrumental support load on one key dimension. The only exception are two items that capture normative support, tapping into pride of one's religion and one's nationality. These two indicators load on a separate factor. However, as religion and nationalism are key to the narrative of the Turkish regime, we keep these items in the index measuring normative support for theoretical reasons. To make sure that this decision is not driving findings, in Appendix 13 we replicate findings dropping these two items from the index. Results remain consistent.

Evidence that, in the Turkish context, normative and instrumental support are intertwined is an important finding that deserves to be discussed carefully. It is possible that normative attachment might have instrumental foundations under authoritarian regimes as voters supporting the ruling party for instrumental reasons might become more receptive to the regime's propaganda and develop norma-

$\overline{15}$ If we divide this into government and non-government voters, then $\mathrm{R}=0.78$ (gov) and $\mathrm{R}=0.72$ (non-gov). 
Table 1: Exploratory factor analysis and pairwise correlations for the political support items and government voters

\begin{tabular}{lcc|cc|c}
\hline \multicolumn{4}{l}{ Government voters } & \multicolumn{3}{l}{ Non-Government voters } & Corr \\
Variable & Factor1 & Factor2 & Factor1 & Factor2 & Gov. voters \\
\hline Normative Support & & & & & \\
Pride: Nation & 0.46 & 0.62 & 0.27 & 0.74 & 0.36 \\
Pride: Religion & 0.42 & 0.72 & 0.39 & 0.72 & 0.45 \\
Ottoman nostalgia & 0.47 & 0.28 & 0.49 & 0.24 & 0.57 \\
Strong leader & 0.67 & 0.06 & 0.64 & 0.04 & 0.60 \\
Elections limited & 0.57 & 0.28 & 0.51 & 0.43 & 0.57 \\
Restrict media & 0.62 & 0.09 & 0.61 & 0.13 & 0.58 \\
AKP: Support nation & 0.74 & -0.04 & 0.65 & -0.12 & 0.64 \\
AKP: Defend Muslims & 0.74 & -0.06 & 0.74 & -0.12 & 0.65 \\
Erdogan: Mission & 0.83 & -0.06 & 0.64 & -0.14 & 0.62 \\
Erdogan: Inspiring & 0.87 & -0.10 & 0.83 & -0.18 & 0.72 \\
Instrumental Support & & & & & \\
Turkey life quality & 0.77 & -0.16 & 0.74 & -0.07 & 0.60 \\
Success: Econ. Minister & 0.78 & -0.15 & 0.71 & -0.08 & 0.65 \\
Success: Erdogan & 0.88 & -0.09 & 0.86 & -0.14 & 0.73 \\
Policy: Economy & 0.85 & -0.19 & 0.81 & -0.12 & 0.66 \\
Policy: Poverty & 0.83 & -0.21 & 0.82 & -0.14 & 0.64 \\
Policy: Security & 0.75 & -0.14 & 0.69 & -0.10 & 0.62 \\
\hline
\end{tabular}

Note: Only factors that have at least an eigenvalue of 1 are retained. The last column reports the pairwise correlation between government voters in 2018 (vs all else) and each support item.

tive support over time. The AKP propaganda in Turkey for example, links references to regime principles with instrumental issues and promises. The strong leader rule is also presented as the only way for creating efficient government and delivering growth. For example, one of the official campaign slogans of Turkey's 2018 general election was “Great Turkey needs a strong leader: Recep Tayyip Erdogan for new bridges, new airports, nation gardens." Survey evidence suggests that this narrative resonates with the AKP supporters; in the last fifteen years, AKP voters became more supportive of the strong leader rule (Schafer 2021). These observations from the Turkish context are also in line with comparative literature demonstrating that people who believe that the incumbent is managing the economy well, also update their regime preferences in a more authoritarian direction (Mazepus and Toshkov 2021; Singer 2018).

Given the relationship between normative and instrumental support, we proceed by presenting analysis that relies on three separate indices of political support. The first of them combines survey questions that capture normative and instrumental support into a single scale. The other two indices rely on theory to disaggregate the aggregate support items into its normative and instrumental components. While the construction of the normative and instrumental support indices is theoretically 
Table 2: Descriptive results: Average levels of combined, normative, and instrumental support by 2018 votes

\begin{tabular}{lcccc}
\hline & \multicolumn{4}{c}{ Vote in 2018 } \\
& All & Government & Opposition & Abstention \\
\hline Combined & 47.4 & 69.4 & 18.6 & 32.3 \\
Normative & 51.3 & 73.4 & 22.5 & 36.0 \\
Instrumental & 40.6 & 62.4 & 11.9 & 25.5 \\
\hline N of obs & 3,834 & 1,827 & 1,550 & 410 \\
\hline
\end{tabular}

Note: All variables range from 0 - no support to 100 - complete support. The results are based on survey 2 , in which items that capture normative and instrumental support were asked before the introduction of the economic treatment, that is before the experiment. The results are weighted by a population weight, which was calculated based on the 2020 census data. See footnote ?? for classifications of 2018 vote.

motivated, in the Turkish context normative support and instrumental support overlap.

Table 2 presents the distribution of the different types of support support in the full sample and considers whether support varies across government and non-government voters. We display the average levels of support in the full sample and across respondents who, in the 2018 election, reported to have voted for the government, the opposition, and to have abstained. Figure 2 further plots the distribution of the support variables for government voters versus non-government voters, clustering together opposition and non-voters. ${ }^{16}$ All support measures presented in this descriptive section are based on Survey 2 in which the support items were asked prior to the framing experiment and rely on a sample of 3,834 respondents.

Looking first at Table 2, we note that in the full sample, the average score for normative support is just over 50 points on a $0-100$ scale, while instrumental support is approximately 10 points points lower. This implies that, across the population at the time of the survey, support for regime norms and principles was higher than support for how the government was performing. It is also noteworthy that average levels of normative support are higher than levels of instrumental support across all voter groups. At the same time, both normative and instrumental support are well above the survey average among government voters. For this group of respondents, the average score for normative support is 73.4. Instrumental support is lower at 62.5. Compared to government voters, non-government voters (opposition voters and those who abstained) report lower levels of both normative and instrumental support. Normative support is lower among opposition than non-government voters (22.5 vs 36.1 ).

\footnotetext{
${ }^{16}$ Based on the results presented in Table 2, opposition and non-voters report similar levels of support. Further, our theory does not expect differences between these groups, unlike government voters, which we expect to have a perceptual bias.
} 
Figure 2: Autocratic system support by 2018 votes
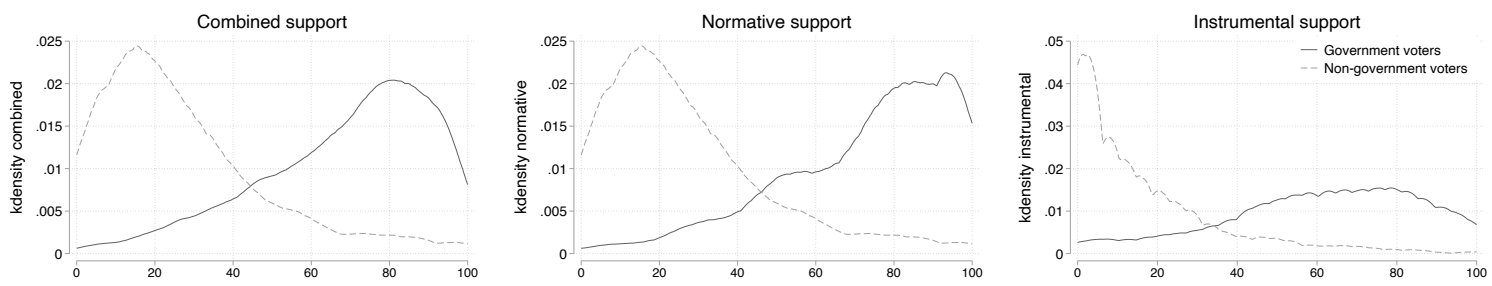

Note: All variables range from 0 - no support to 100 - complete support. The results are based on survey 2 , in which the regime support variables were asked before the introduction of the economic treatment. The results are weighted by a population weight.

The same is true for instrumental support, which ranges around 12 points for opposition voters and 26 points for non-voters.

The distribution of support in Figure 2 provides additional evidence of attitudinal polarization in the Turkish electorate (e.g. Laebens and Öztürk 2021). The largest share of non-government voters clusters along the lowest scores of normative (left-hand plot) and instrumental support (righthand plot). The opposite is true for government voters. The evidence suggests that divisions in how government and opposition voters evaluate the authorities extend beyond instrumental support. Government and opposition voters also differ in how they assess the political system and in how closely they identify with the principles of the ruling regime.

\subsection{Political System Support and Economic Performance}

Relying on evidence from Survey 1, in which support measures are asked after the framing experiment, Figure 3 shows how our experiment, which provides respondents in the treatment group information about the economic performance in Turkey, influences different forms of support. Figure 3 reports the regression coefficients and $95 \%$ confidence intervals of the crisis treatment on the different forms of political support for government (top panel) and non-government (bottom panel) voters. Each outcome was estimated separately using linear regressions and do not include any pre-treatment controls, given that we achieved balance between the treatment and control group for survey 1 (see Appendix 6). The analysis presented here empirically tests Hypothesis 1, regarding the resilience or responsiveness of different forms of support to poor economic performance.

We theoretically anticipated that normative support will be less responsive to policy outputs, here 
Figure 3: Impact of crisis treatment on autocratic system support: Regression coefficients and 95\% confidence intervals.
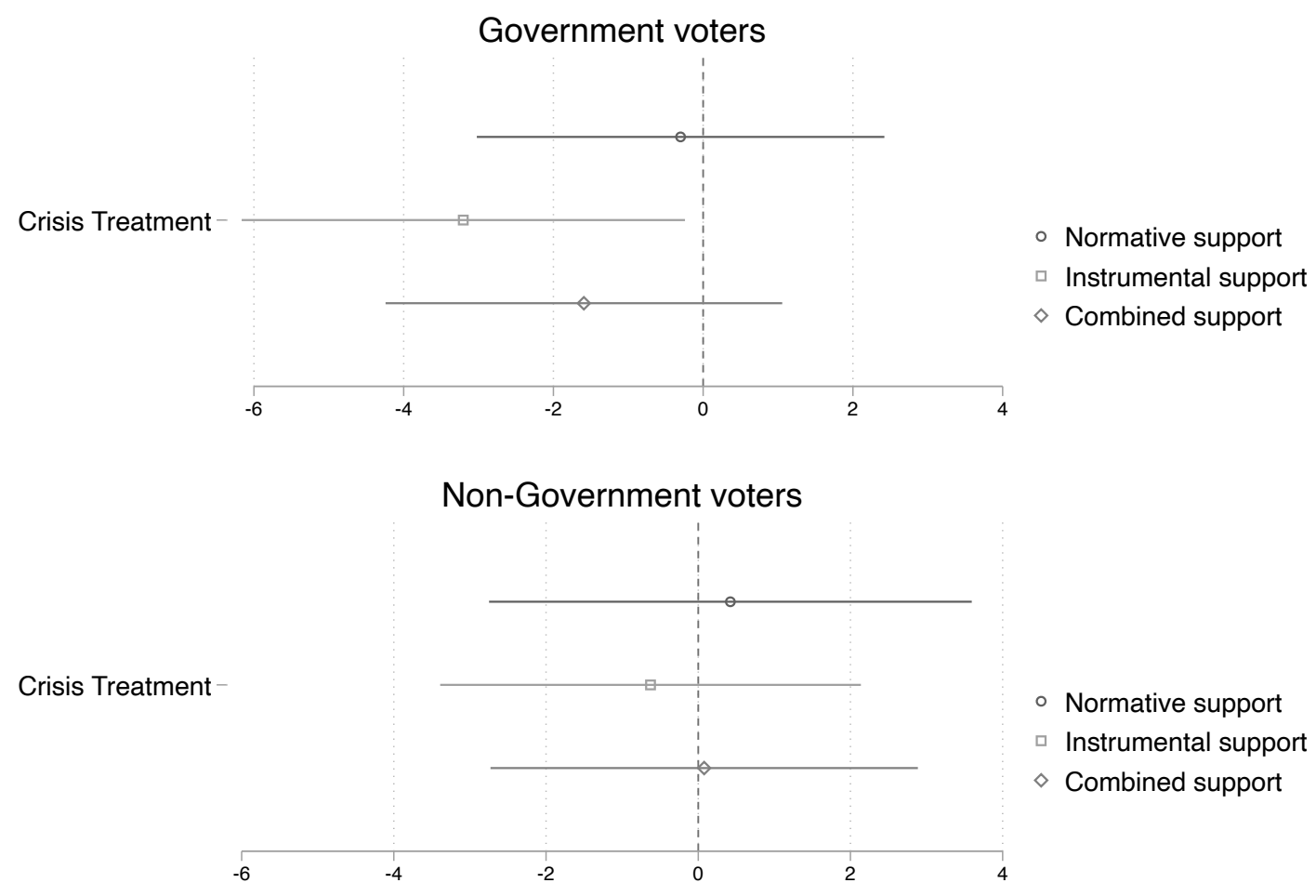

Note: The graph displays the regression coefficient of the economic crisis treatment on system support outcome variables. Support variables range from 0 - no support to 100 - complete support. The results are based on survey 1, in which the regime support variables were asked after the introduction of the economic treatment. The analysis are based on linear regression models with no control variables. Number of observations: 1,126 (government voters) and 871 (non-government voters). Full results are available in Appendix 7.

information about poor performance, than instrumental support. Figure 3 shows this to be the case for government voters. Government voters primed on the economy have 3.1 points lower instrumental support compared to the control group. This effect is significant on the $5 \%$ level. Normative support, as well as the measure of support that brings together normative and instrumental assessments do not shift in response to information about poor economic performance. The economic crisis treatment does not shift support among voters who did not vote for governing parties. To some extent, flooring effects may account for this finding. Non-government voters report low levels of instrumental, normative, and combined support to begin with and are not easily moved by the treatments. In a similar vein, the treatments may be revealing no new or helpful information for non-government voters, in a way that could help with attitudinal updating.

Figure A.2 in Appendix 8 additionally reports the results for each of the 16 survey items used in the 
Figure 4: Impact of crisis treatment on vote likelihood and AKP mobilization: Regression coefficients and $95 \%$ confidence intervals.
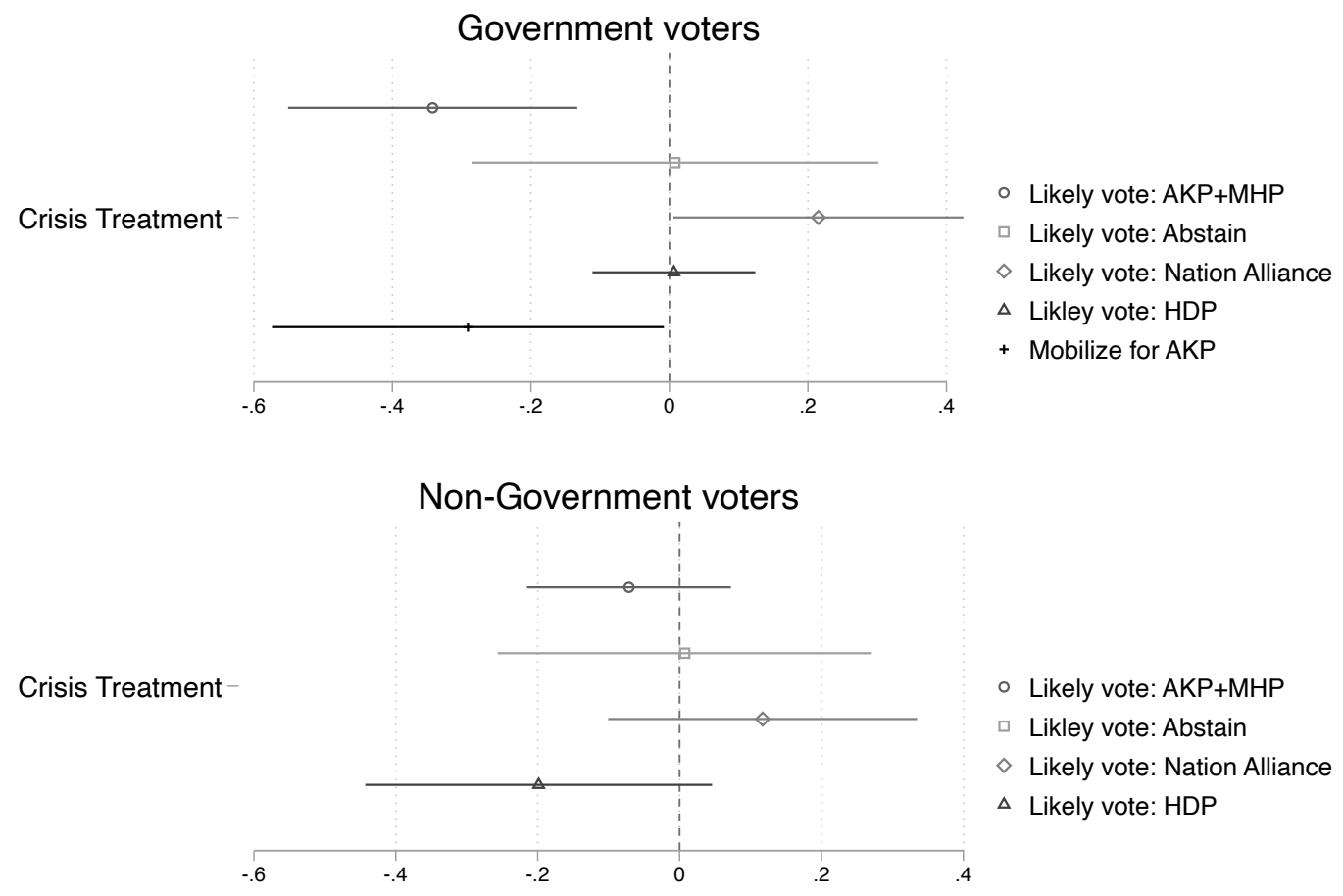

Note: The graph displays the regression coefficient of the economic crisis treatment on behavioural outcome variables of government or opposition support. All outcome variables range from 1 - not likely at all to 7 - very certain. The results are based on survey 2, in which the system support variables were asked before the introduction of the economic treatment. The analysis are based on linear regression models, controlling for income (for gov. voters' sample). Full results are available in Appendix 7.

analysis, only for the sub-sample of government voters. The only items that show a significant (on the $5 \%$ level) negative impact of the treatment relate to instrumental support items: the evaluation of the quality of life in Turkey, the rating of the economy minister, and the policy rating of the economy. Evaluations of Erdogan himself however seem to be resilient to the crisis treatment. None of the items that measure normative support is significantly moved by the economic crisis treatment. The same holds if we drop the items that tap into national and religious pride from the index of normative support (see Figure A.7 in Appendix 13). 


\subsection{System Support, Economic Performance, and Electoral Support for the Governing Parties}

In this section, we test our second set of hypotheses. In a first step, we look at the direct effect of the crisis treatment on behavioral support for the regime. Figure 4 shows the coefficients of the treatment (compared to the control group) on the likelihood to vote for the governing parties - AKP or MHP, to abstain, to vote for the Nation Alliance (a group of opposition parties), or the HDP (the Kurdish opposition party). We further regress on the likelihood to mobilize for the AKP in an upcoming election. The top panel of Figure 4 focuses on government voters and the bottom panel on nongovernment voters, as per their reported vote in the 2018 election. The results are based on linear regression and control for income in the sample of government voters, given the imbalance in income between the treatment and control group for survey 2 (see Appendix 6).

The results lend support for Hypothesis 2. Among government voters, information about poor performance significantly suppresses support for the AKP - reducing individuals' willingness to vote for the AKP and to mobilize in support of the party. The treatment further significantly increases the likelihood of past AKP voters voting for the Nation Alliance. ${ }^{17}$ We do not find behavioral changes for non-governmental voters. Altogether, findings confirm that electoral authoritarian regimes are at risk of losing electoral support among their voters, getting punished for bad economic performance. The results also show that opposition parties can win votes from government supporters at times of crisis. The evidence follows classic economic voting literature, established in advanced democracies, and agrees with research on economic voting under electoral authoritarianism (e.g. Lewis-Beck and Stegmaier 2007; Treisman 2011; Rosenfeld 2020). While prior works rely primarily on observational data, ours is one of the first studies to causally identify the effect of poor performance on vote intention and pro-regime mobilization in a non-democracy.

At the same time, aggregate findings regarding the consequences of poor performance may mask important heterogeneity in the effects of the crisis. In line with theoretical expectations, we anticipate that political support could condition the electoral consequences of poor economic performance. In a next step, we therefore condition the economic crisis treatment on the different forms of support,

\footnotetext{
${ }^{17}$ In Appendix 9 we additionally presents results that look at vote switching between the 2018 election and vote intention today. Findings confirm that the treatment has a significant and positive effect on defection of government voters who switch from the governing to opposition parties. None of the other possible vote change categories is significant.
} 
Figure 5: Interaction between economic crisis treatment and system support on the likelihood to vote for government parties. Marginal effects and 95\% confidence intervals. Government voters only
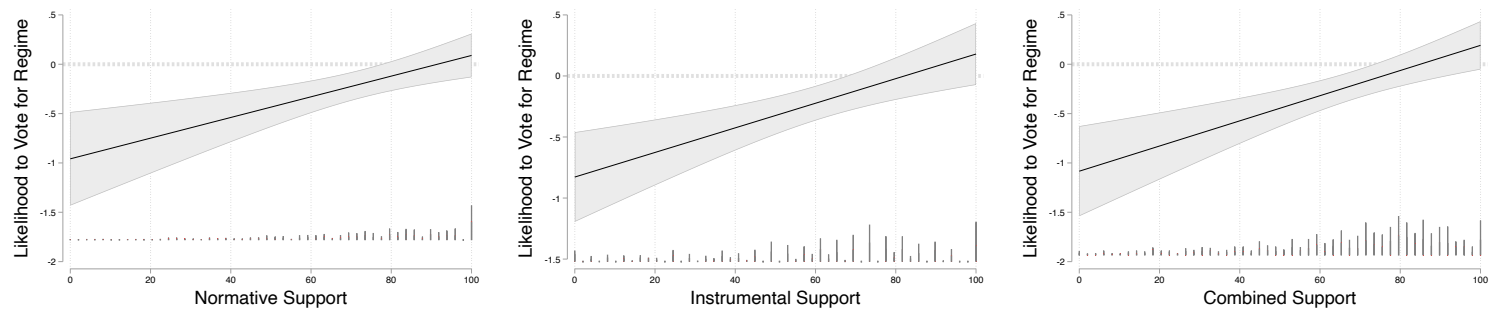

Note: The graph displays the marginal effect of the economic crisis treatment on the likelihood to vote for the government parties. The outcome ranges from 1 - not likely at all to 7 - very certain. The results are based on survey 2, in which the regime support variables were asked before the introduction of the economic treatment. The analysis are based on linear regression models, controlling for income. Full results are available in Appendix 7.

using support items measured before respondents were exposed to the treatment. Figure 5 plots the marginal effects of the treatment and its impact on the likelihood to vote for the governing parties by the level of normative (left-hand plot), instrumental (middle plot), and overall (right-hand plot) support. Findings suggest that political support has a resilience effect, yet only at the highest levels of the support values. For all forms of support - whether normative, instrumental, or the combination of the two - the crisis treatment does not have a significant impact at high levels of support, but is negative at low levels of support. For example, in the context of our study, $45 \%$ of government voters have normative support above 80 , at which point the crisis treatment becomes insignificant. Similarly, $45 \%$ of government voters have instrumental support above 70 , at which point the crisis treatment becomes insignificant. For every other group, poor economic performance is associated with a significant decrease in the probability of voting for the regime. For example, the treatment reduces the likelihood of AKP voters who report the lowest possible levels of normative support to vote for the governing parties by 1.2 points on a 1 to 7 scale. This is a considerably strong effect. ${ }^{18}$

In sum, while the results show that the government is vulnerable to losing support due to poor economic performance, the threat of defections is mitigated at the highest levels of political support. As such, the distribution of voters across the political support spectrum, which varies across authoritarian regimes, can influence the electoral consequences of poor performance. In contexts where only

\footnotetext{
${ }^{18}$ In Appendix 10 we further display the interaction effects for each of the 16 included survey items separately. The results confirm that all items follow the same pattern as displayed in Figure 5, which uses our two latent indices. The only exception is religious pride. Appendix 11 further presents results of the interaction effect between the crisis treatment and the support variables on the likelihood to mobilize for the AKP. The results follow a similar pattern than for vote intentions, but are generally weaker.
} 
a minority of voters fit into the category of 'extreme' supporters, defections from the ruling regime party will be of far greater extent.

Altogether, findings reported in Figure 5 lend support for Hypothesis 3a, which expects political support to condition the effect of poor performance on voter defections. However, the results do not provide evidence for Hypothesis $3 b$. We do not find a significant difference in the conditioning effect of normative and instrumental support. Comparing the marginal effects as well as the slope, there are no differences between the two forms of regime support (see also the estimates in Table A.8 in Appendix 7). Given that, in the Turkish context, normative and instrumental support largely overlap, this finding is unsurprising.

One possible explanation for the finding in Figure 5 could relate to differences in how individuals assign blame for poor performance (Tilley et al. 2018). According to an argument, incumbents can eschew punishment for economic downturns if voters blame other factors and actors for the decline. For example, Rozenas and Stukal (2019) demonstrate that state-controlled media in Russia associate good economic news with Putin and the regime and negative economic developments with external factors.

Additional analyses, presented in Appendix 12, demonstrate that among voters with lower normative support, blame attribution for Erdogan mediates $45 \%$ of the relationship between the crisis treatment and the likelihood to vote for the AKP. It is therefore possible that, under conditions of economic decline, voters who have lower normative support become less likely to vote for the regime because they hold Erdogan responsible for the economic crisis. Yet, for voters with higher normative support, the crisis treatment does not even have a positive effect on blame assigned to Erdogan, hence no mediating effect as well. Instead, government voters with higher levels of normative support increase the blame assigned to external factors and become even more likely to vote for regime parties. These results help us to better understand the relationship between regime support and voter loyalty in times of crisis.

\subsection{Evidence from observational data}

The empirical analysis has so far relied on online surveys which are based on convenient samples and use a survey experiment to artificially frame the treatment of the economic crisis. To test whether experimental findings are generalizable, we replicate the analysis drawing on a face-to-face repre- 
Figure 6: Impact of negative economic evaluations (marginal effects and 95\% confidence interval) by feeling thermometer score for the AKP on 2018 vote for the AKP.

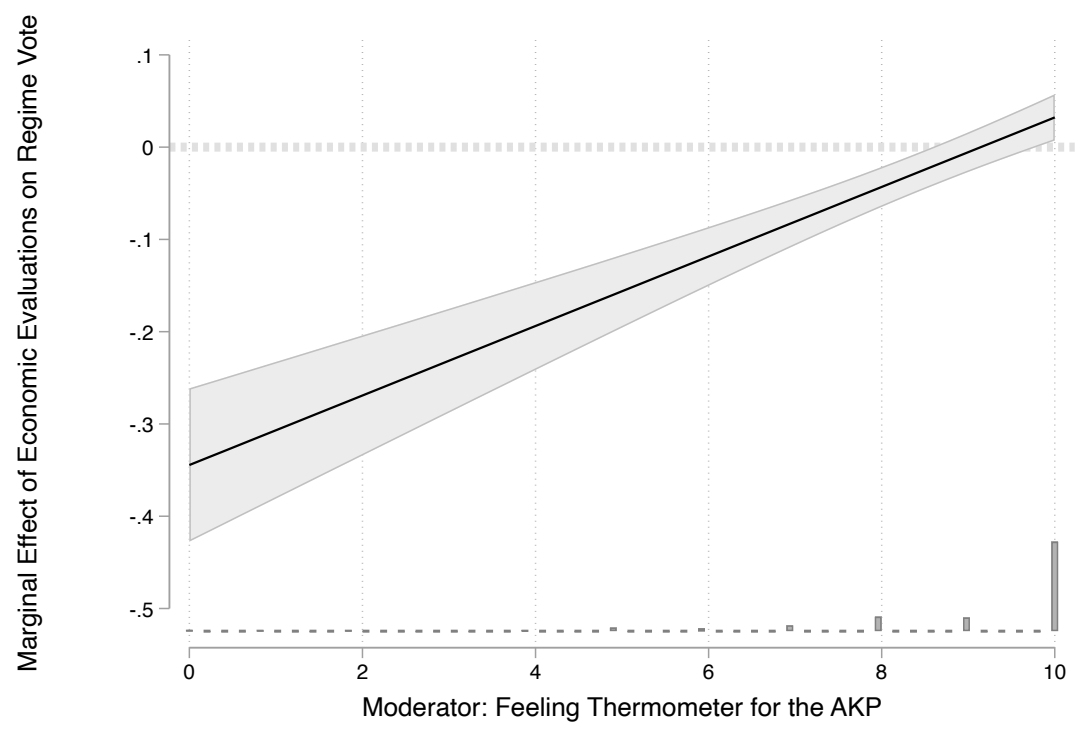

Note: The graph displays the marginal effect of sociotropic economic evaluations, which ranges from 1 the state of economy has gotten much better over the past year to 5 - state of economy has gotten much worse over the past year. The analysis is based on linear regression model, controlling for age, education, gender, and household income. Sample is limited to people who voted for the AKP in the previous national election in 2015.

sentative survey fielded after the 2018 General Election in Turkey. The survey was fielded as part of the Comparative Study of Election Studies (CSES) project.

2018 was a year of economic hardship for Turkish voters. One month before the election the official economic confidence index dropped to the lowest point of the last fifteen months as the value of Turkish lira continued to decline (see also Figure 1). CSES survey data demonstrates that only half of AKP voters, and a mere $6 \%$ of the remaining electorate, believed that the economy had improved compared to the previous year. Yet, the ruling AKP-MHP coalition won the 2018 General Election with $54 \%$ of the votes.

Our analysis, presented in Figure 6, explores whether political support, proxied through individuals' attachments to the AKP, conditioned the relationship between sociotropic economic evaluations and vote choice in the 2018 General Election. ${ }^{19}$ In this context, we operationalize political support using feeling thermometer scores for the AKP. Feeling thermometers are widely used to capture voters' affective attitudes toward political parties (Druckman and Levendusky 2019). In contrast to more

\footnotetext{
${ }^{19}$ Kernel density distributions for AKP voters' feeling thermometer scores and sociotropic economic evaluations are provided in Appendix 17.
} 
evaluative measures, which would tap into instrumental support, feeling thermometers may mainly, but not exclusively, capture normative attachments to the political system. Following the experimental design, the sample is limited to respondents who voted for the AKP in the previous election in 2015. We hence model whether AKP voters remain loyal to the party in the subsequent 2018 election, which happened during a severe economic crisis.

In line with the experimental findings, we find that normative considerations condition the relationship between economic perceptions and support for the governing parties. Negative economic evaluations do not lead to defections among AKP voters who "strongly like" the party. While negative economic evaluations decrease the likelihood of voting again for the AKP among voters who lack affective ties to the party, the strongest supporters remain unaffected. If anything, for respondents who most strongly like the party (score of 10), a negative economic evaluation even increases the probability to vote for the AKP again, leading to a kind of rallying effect. Thus, the AKP needs voters harboring strong affective attachments to the party to survive the economic crisis without losing crucial electoral support.

\section{Conclusion}

While an influential literature recognizes that authoritarian regimes enjoy popular support (Frye et al. 2017), mass support for authoritarian rule is mainly viewed as performance-based or instrumental in nature (Huhe and Tang 2017). Autocrats are typically shown to earn support by delivering public and private goods (Desai et al. 2009). Value-based or normative support for the political system is argued to mainly exists in democracies (Huhe and Tang 2017) or to be restricted to national and religious identities (e.g. Kuzio 2016). To some extent, data availability has limited our ability to test for congruence in the values and norms of citizens and those of authoritarian regimes. Existing survey data, available for a range of regimes, focus primarily on measuring support for the norms and principles of democratic, as opposed to authoritarian regimes (Booth et al. 2009: 14). In a similar vein, partisanship items do not allow us to explore the role of values and principles in generating political system support.

In this paper we rely on a mix of established and new survey indicators to capture the different aspects of normative and instrumental system support. Context-specific survey indicators have allowed us to go beyond the existing focus on partisanship in Turkey and to tap into principles and norms 
specific to the contemporary Turkish regime. Exploratory analysis suggests that, in the Turkish context, normative and instrumental support are intertwined. While typically considered as theoretically distinct, normative and instrumental support are empirically indistinguishable. Evidence also suggests that government voters report high levels of both normative and instrumental support, and that support for the political system is polarized between government and opposition voters.

Drawing on two framing experiments that prime respondents to consider the deterioration in national economic performance, we find that, in line with Eastonian theory, normative forms of political support are less influenced by poor economic performance than instrumental ones. Findings also suggest that the political consequences of economic downturns are conditional on prior system support: government voters who report the highest levels of support for the political system are unaffected by negative economic performance and less likely to defect from the AKP. In other words, pre-existing political system support acts 'as a reservoir' of support that can immunize a regime in poor economic times. Authoritarian regimes can rely on a group of core loyal voters who will continue to support the regime even if performance falters. Core supporters' share across contexts may play an important role in determining the extent to which economic downturns or poor policy performance more broadly will have adverse political consequences.

Our research and findings have several implications. Firstly, our work underscores the importance of relying on survey items that better capture the distinct principles, norms, and structures of contemporary authoritarian regimes. Second, findings revive the original Eastonian intuition that political systems can have and need political support to tide them over in times when policy performance will inevitably suffer. By revisiting the importance of normative support for authoritarian rule, and emphasizing its close relationship with instrumental assessments, our work identifies another avenue that could compromise electoral punishment in contemporary electoral autocracies. Thirdly, findings regarding the importance of high levels of support for the political system may also help explain the revived interest in political education across many authoritarian regimes ranging from China to Russia and others. Education and political socialization consist of key channels through which incumbents may build and sustain normative support. Nevertheless, more research is needed in order to better understand the origins of instrumental and normative support in authoritarian regimes and the role that regime indoctrination and propaganda might play in sustaining them. 


\section{References}

Aliriza, Bulent. 2018. "Erdogan Takes Total Control of "New Turkey"." Center for Strategic and International Studies.

URL https://www.csis.org/analysis/erdogan-takes-total-control-new-turkey

Aytaç, Selim Erdem. 2021. "Effectiveness of Incumbent's Strategic Communication during Economic Crisis under Electoral Authoritarianism: Evidence from Turkey.” American Political Science Review 115(4):1517-1523.

Beazer, Quintin H and Ora John Reuter. 2019. "Who is to blame? Political centralization and electoral punishment under authoritarianism." The journal of politics 81(2):648-662.

Bermeo, Nancy. 2016. “On democratic backsliding.” Journal of Democracy 27(1):5-19.

Bølstad, Jørgen, Elias Dinas, and Pedro Riera. 2013. "Tactical voting and party preferences: A test of cognitive dissonance theory." Political behavior 35(3):429-452.

Booth, John A, Mitchell A Seligson, et al. 2009. The legitimacy puzzle in Latin America: Political support and democracy in eight nations. Cambridge University Press.

Carlin, Ryan E and Matthew M Singer. 2011. "Support for Polyarchy in the Americas." Comparative political studies 44(11):1500-1526.

Çelik, Ayşe Betül and Evren Balta. 2020. "Explaining the micro dynamics of the populist cleavage in the 'new Turkey'." Mediterranean Politics 25(2):160-181.

Claassen, Christopher and Pedro C Magalhães. 2021. "Effective government and evaluations of democracy." Comparative Political Studies page 00104140211036042.

Cleary, Matthew R and Aykut Öztürk. 2020. "When Does Backsliding Lead to Breakdown? Uncertainty and Opposition Strategies in Democracies at Risk." Perspectives on Politics pages 1-17.

Dalton, Russell. 1999. "Political Support in Advanced Democracies." In Critical citizens: Global support for democratic government, Norris Pippa, ed., chap. 3, Oxford: Oxford University Press.

Desai, Raj M, Anders Olofsgård, and Tarik M Yousef. 2009. "The logic of authoritarian bargains." Economics \& Politics 21(1):93-125.

Druckman, James N and Matthew S Levendusky. 2019. "What do we measure when we measure affective polarization?" Public Opinion Quarterly 83(1):114-122.

Dukalskis, Alexander and Junhyoung Lee. 2020. "Everyday nationalism and authoritarian rule: A 
case study of North Korea.” Nationalities Papers 48(6):1052-1068.

Easton, David. 1965a. "A Framework for Political Analysis." Englewood Cliffs, HJ: Prentice-Hall .

Easton, David. 1965b. “A Systems Analysis of Political Life.”

Easton, David. 1975. "A re-assessment of the concept of political support.” British journal of political science 5(4):435-457.

Elçi, Ezgi. 2021. "Politics of Nostalgia and Populism: Evidence from Turkey." British Journal of Political Science pages 1-18.

Esen, Berk and Şebnem Gümüş̧̧ü. 2017. "A small yes for presidentialism: The Turkish constitutional referendum of April 2017." South European Society and Politics 22(3):303-326.

Esen, Berk and Şebnem Yardimci-Geyikçi. 2020. "The Turkish presidential elections of 24 June 2018." Mediterranean Politics 25(5):682-689.

Evans, Geoffrey and Mark Pickup. 2010. "Reversing the causal arrow: The political conditioning of economic perceptions in the 2000-2004 US presidential election cycle." The Journal of Politics 72(4):1236-1251.

Frye, Timothy, Scott Gehlbach, Kyle L Marquardt, and Ora John Reuter. 2017. “Is Putin's popularity real?" Post-Soviet Affairs 33(1):1-15.

Fuchs, Dieter. 2007. “The political culture paradigm.” In The Oxford handbook of political behavior.

Geddes, Barbara. 1999. "What Do We Know About Democratization After Twenty Years?" Annual Review of Political Science 2(1):115-144.

URL https://doi.org/10.1146/annurev.polisci.2.1.115

Geddes, Barbara and John Zaller. 1989. "Sources of popular support for authoritarian regimes." American Journal of Political Science pages 319-347.

Gerber, Alan S and Gregory A Huber. 2010. "Partisanship, political control, and economic assessments." American Journal of Political Science 54(1):153-173.

Gerschewski, Johannes. 2018. "Legitimacy in Autocracies: Oxymoron or Essential Feature?" Perspectives on Politics 16(3):652-665.

Gill, Anthony J. 2019. Rendering unto Caesar? Religious competition and Catholic political strategy in Latin America, 1962-79. Routledge.

Guriev, Sergei and Daniel Treisman. 2020. "The Popularity of Authoritarian Leaders: A Cross- 
National Investigation.” World Politics 72(4):601-638.

Hale, Henry. 2015. Patronal Politics: Eurasian Regime Dynamics in Comparative Perspective. Cambridge University Press.

Hale, Henry E. 2011. "The myth of mass Russian support for autocracy: The public opinion foundations of a hybrid regime.” Europe-Asia Studies 63(8):1357-1375.

Hale, Henry E and Timothy J Colton. 2017. "Who Defects? Unpacking a Defection Cascade from Russia’s Dominant Party 2008-12.” American Political Science Review 111(2):322-337.

Hellmeier, Sebastian, Rowan Cole, Sandra Grahn, Palina Kolvani, Jean Lachapelle, Anna Lührmann, Seraphine F Maerz, Shreeya Pillai, and Staffan I Lindberg. 2021. "State of the world 2020: autocratization turns viral." Democratization pages 1-22.

Hirschman, Albert O. 1970. Exit, Voice, and Loyalty: Responses to Declines in Firms, Organizations, and States. Cambridge, MA: Harvard University Press.

Huhe, Narisong and Min Tang. 2017. "Contingent instrumental and intrinsic support: Exploring regime support in Asia." Political Studies 65(1):161-178.

Karagiannis, Emmanuel. 2016. "The new face of political Islam in Central Asia: The rise of Islamodemocrats." Journal of Muslim Minority Affairs 36(2):267-281.

Klingemann, Hans-Dieter and Dieter Fuchs, eds. 1995. Citizen and the State. Oxford: Oxford University Press.

Koesel, Karrie J., Valerie Bunce, and Jessica Weiss, eds. 2020. Citizens and the State in Authoritarian Regimes: Comparing China and Russia. New York: Oxford University Press.

Kuzio, Taras. 2016. "Nationalism and authoritarianism in Russia: Introduction to the special issue." Communist and post-communist studies 49(1):1-11.

Laebens, Melis G and Aykut Öztürk. 2021. "Partisanship and autocratization: Polarization, power asymmetry, and partisan social identities in Turkey.” Comparative Political Studies 54(2):245279.

Levy, Jack S. 2008. "Case studies: Types, designs, and logics of inference.” Conflict management and peace science 25(1):1-18.

Lewis-Beck, Michael and Mary Stegmaier. 2007. "Economic Models of Voting." In The Oxford handbook of political behavior, OUP Oxford.

Lührmann, Anna, Sandra Grahn, Richard Morgan, Shreeya Pillai, and Staffan I Lindberg. 2019. 
"State of the world 2018: democracy facing global challenges." Democratization 26(6):895-915.

Magaloni, Beatriz. 2006. Voting for Autocracy: Hegemonic Party Survival and its Demise in Mexico.

Cambridge Studies in Comparative Politics, Cambridge University Press.

Matovski, Aleksandar. 2021. Popular Dictatorships: Crises, Mass Opinion, and the Rise of Electoral Authoritarianism. Cambridge University Press.

Mauk, Marlene. 2020. Citizen Support for Democratic and Autocratic Regimes. Oxford: Oxford University Press.

Mazepus, Honorata and Dimiter Toshkov. 2021. "Standing up for Democracy? Explaining Citizens' Support for Democratic Checks and Balances." Comparative Political Studies page 00104140211060285 .

Norris, Pippa, ed. 1999. Critical Citizens: Global Support for Democratic Government. Oxford: Oxford University Press.

Norris, Pippa. 2011. Democratic Deficit. Critical Citizens Revistied. Cambridge: Cambridge University Press.

O’Donell, Guillermo A. 1994. “Delegative democracy.” Journal of democracy 5(1):55-69.

Rose, Richard and William Mishler. 1996. "Testing the Churchill hypothesis: Popular support for democracy and its alternatives.” Journal of public policy 16(1):29-58.

Rosenfeld, Bryn. 2020. "State Dependency and the Limits of Middle Class Support for Democracy." Comparative Political Studies .

Rozenas, Arturas and Denis Stukal. 2019. "How autocrats manipulate economic news: Evidence from Russia's state-controlled television.” Journal of Politics 81(3):982-996.

Schafer, Dean. 2021. "A Popular Mandate for Strongmen: What Public Opinion Data Reveals About Support for Executive Aggrandizement in Turkey, 1996-2018.” South European Society and Politics 26(3):355-382.

Schedler, Andreas and Rodolfo Sarsfield. 2007. "Democrats with adjectives: Linking direct and indirect measures of democratic support." European journal of political research 46(5):637-659.

Shin, Doh Chull. 2021. "Democratic deconsolidation in East Asia: exploring system realignments in Japan, Korea, and Taiwan.” Democratization 28(1):142-160.

Singer, Matthew. 2018. "Delegating away democracy: How good representation and policy successes can undermine democratic legitimacy." Comparative Political Studies 51(13):1754-1788. 
Svolik, Milan W. 2019. “Polarization versus democracy.” Journal of Democracy 30(3):20-32.

Taş, Hakk1. 2015. "Turkey-from tutelary to delegative democracy." Third World Quarterly 36(4):776-791.

Tilley, James, Anja Neundorf, and Sara B Hobolt. 2018. "When the pound in people's pocket matters: How changes to personal financial circumstances affect party choice." Journal of Politics 80(2):555-569.

Treisman, Daniel. 2011. "Presidential popularity in a hybrid regime: Russia under Yeltsin and Putin." American journal of political science 55(3):590-609.

Treisman, Daniel. 2014. "Putin's popularity since 2010: why did support for the Kremlin plunge, then stabilize?" Post-Soviet Affairs 30(5):370-388.

Waldman, Simon and Emre Caliskan. 2017. The New Turkey and its discontents. Oxford University Press.

Yabanci, Bilge. 2020. "Fuzzy borders between populism and sacralized politics: Mission, leader, community and performance in 'New'Turkey.” Politics, Religion \& Ideology 21(1):92-112.

Yavuz, M Hakan. 2020. Nostalgia for the Empire: The Politics of Neo-Ottomanism. Oxford University Press.

Yilmaz, Ihsan. 2018. "Islamic populism and creating desirable citizens in Erdogan's new Turkey." Mediterranean Quarterly 29(4):52-76.

Yilmaz, Ihsan and Galib Bashirov. 2018. "The AKP after 15 years: emergence of Erdoganism in Turkey." Third World Quarterly 39(9):1812-1830. 


\title{
A Loyal Base: \\ Support for Authoritarian Regimes in Times of Crisis
}

\author{
Supplementary Analysis
}

\section{Contents}

1 Power Analysis $\quad 3$

2 Recruitment through Facebook $\quad 4$

3 Comparing sample characteristics with 2020 Census Data 5

4 Measurement of key variables 6

4.1 Normative and instrumental system support . . . . . . . . . . . . . . . . 6

4.1.1 Normative support ..................... 6

4.1.2 Instrumental support . . . . . . . . . . . . . . . . . 6

4.1.3 Exploratory factor analysis of system support items . . . . . . . . . . 7

4.2 Pro-government behavioral support . . . . . . . . . . . . . . . . 9

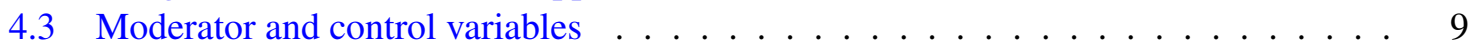

5 Additional analysis: List experiment 11

5.1 Full list of items used in list experiment . . . . . . . . . . . . . . . . . . 11

5.2 Results of list experiment using different ways to measure middle category . . . . . . 14

6 Balance test $r$

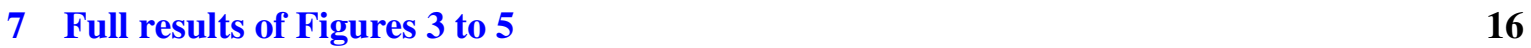

8 Additional results H1 (Fig 3): Single survey items for regime support 18

9 Additional results H2 (Fig 4): Vote change variable as outcome 19

10 Additional results for $\mathrm{H3a}+\mathrm{b}$ (Fig 5): Single survey items for pro-government behavioural support: Interaction between treatment and system support

11 Additional results for $\mathrm{H3a+b}$ (Fig 5): Conditional of economic treatment on mobilization for AKP by of system support

12 Mechanisms behind the lack of defection: Blame attributions 22

12.1 Blame assignment and normative support . . . . . . . . . . . . . . . . . 22

12.2 Blame assignment and instrumental support . . . . . . . . . . . . . . . . 24

13 Robustness tests dropping pride items from normative index 29 
15 Perceptual screen of regime support on economic evaluations 32

16 Divergences to registration $\quad 33$

16.1 Hypotheses on blame attribution $\ldots \ldots \ldots \ldots \ldots \ldots \ldots \ldots$

16.2 Support for political objects . . . . . . . . . . . . . . . . . . . 33

16.3 Political trust items and instrumental support $\ldots \ldots \ldots \ldots \ldots \ldots$

17 Distribution of variables in representative survey 41 


\section{Power Analysis}

We focused on number of regime voters (based on 2018 vote) to calculate minimum required sample size, as we needed enough power to conduct sub-group analysis (H4).

Our targeted sample size was informed by power calculations and expectations derived from the scholarly literature on sample size requirements of statistical models that will be used in this study. We calculated the required sample size for a two-sample comparison of means using sampsi command in Stata. We relied on group means estimates from a pre-test that we conducted before finalizing our study plan, using the same treatment and question design with our original survey. The outcome variable in this pre-test was the difference between post-treatment and pre-treatment scores of economic evaluations among regime voters. In the treatment group, the mean change was -0.14 (sd: 0.61) while in the control group, the mean change was 0.08 (sd: 0.52). Based on these numbers, here is the sample size requirements calculated by Stata:

- Required sample size for 0.05 alpha and 0.8 power: 210

- Required sample size for 0.05 alpha and 0.9 power: 280

- Required sample size for 0.05 alpha and 0.95 power: 346

This analysis demonstrated that the sample required to detect the effects of our treatment with 0.80 power should include at least 210 respondents. However, we will not be able to measure pretreatment levels in other variables in the original survey, meaning that there will be less precision in our estimates (Clifford et al. 2021). Furthermore, we will be testing interaction effects and conducting factor analysis in Survey 2, which will also increase the required minimum sample size. Based on these, we decided to increase our targeted sample around four times for Survey 1 and around eight times for Survey 2. 


\section{Recruitment through Facebook}

We paid Facebook to circulate 12 different recruitment ads on its social media platforms varying based on following characteristics: 1) incentive, 2) advertisement text, and 3) advertisement image. In all ads, social media users were invited to participate in an online survey.

\section{Incentives:}

1. No incentives: One group of participants saw ads not mentioning any incentives.

2. Direct payment (7 TL/£0.6 to everyone): One group of participants were offered Turkish discount store vouchers. In this group, only regime voters (voted for AKP or MHP in the 2018 elections) were eligible. This group was set to a maximum of 500 completed surveys.

3. Low lottery (draw for 50TL/4.3£ discount store voucher): One group of participants were offered access to a lottery for one of seventy vouchers. This group was set to a maximum of 500 completed surveys.

4. High lottery (one iPad, worth $£ 300$ ): Finally, a group of participants were offered access to a lottery for one iPad, worth $£ 300$. This group was set to a maximum of 500 completed surveys.

Participants were eligible to get paid the direct payment or enter the lotteries only if they complete the survey and provide contact details, as otherwise we would not be able to make the payment or contact them in case, they won the lottery. Vouchers will be sent via SMS messages.

\section{Advertisement text:}

1. Vague frame: "Would you like to participate in our survey?"

2. Political frame: "We would like to hear your opinions about politics!"

3. Egotistic frame: "You have been specifically selected among Facebook users."

\section{Advertisement Images:}

1. Neutral image (microphones)

2. Image of the incentive

3. Human photos: These images will show images of individuals, varying the gender of the person in the picture.

To recruit participants, we used the Facebook Business Manager, which allowed us to manage the ads and to see progress in recruitment (e.g. how many people have seen our ad and have clicked on it). We used conversion as campaign objective choice, which helped us to optimize Facebook's algorithm through people completing our surveys. Except age (minimum of 18), we did not constrain the recruitment to any specific parameters, which implies that theoretically any adult using these platforms could see our ad and is hence invited to participate. Samples recruited through Facebook usually end up over-representing college-educated and male people. To create a more balanced sample, we spent additional campaign budget to show our advertisements to a larger number of non-college graduates and female Turkish voters, using Facebook's targeting algorithm. 


\section{Comparing sample characteristics with 2020 Census Data}

Table A.1: Percentages for demographic and political properties in the Turkish population, original sample, and weighted sample

\begin{tabular}{|c|c|c|c|c|}
\hline & & Population $^{1}$ & Sample & Weighted $^{2}$ \\
\hline \multirow[t]{9}{*}{ Regions } & Istanbul & 18.93 & 23.81 & 18.48 \\
\hline & Aegean Region & 13.58 & 15.21 & 13.53 \\
\hline & Ankara & 7.01 & 7.91 & 6.91 \\
\hline & Mediterranean Region & 12.65 & 13.7 & 12.68 \\
\hline & Southeastern Anatolia Region & 9.01 & 5.93 & 9.47 \\
\hline & Eastern Anatolia Region & 6.63 & 3.77 & 6.87 \\
\hline & Black Sea Region & 10.1 & 8.21 & 10.05 \\
\hline & Marmara - excluding Istanbul & 12.8 & 12.4 & 12.73 \\
\hline & Central Anatolia - excluding Ankara & 9.28 & 9.07 & 9.27 \\
\hline \multirow[t]{3}{*}{ Age Groups } & $18-34$ & 36.59 & 31.54 & 29.63 \\
\hline & $35-54$ & 38.18 & 41.62 & 45.2 \\
\hline & $55-65+$ & 25.23 & 26.83 & 25.17 \\
\hline \multirow[t]{2}{*}{ Gender } & Female & 50.32 & 35.79 & 50.18 \\
\hline & Male & 49.68 & 64.21 & 49.82 \\
\hline \multirow[t]{3}{*}{ Education } & Under High School & 55.26 & 26.04 & 55.26 \\
\hline & High School & 25.09 & 52.26 & 25.09 \\
\hline & College & 19.65 & 21.69 & 19.65 \\
\hline \multirow{2}{*}{$\begin{array}{l}\text { Election Turnout } \\
\text { (2018 Election) }\end{array}$} & Voted & 86.22 & 88.83 & 91.15 \\
\hline & Not voted & 13.78 & 11.17 & 8.85 \\
\hline Vote Choice & $\mathrm{AKP}$ & 42.56 & 45.45 & 49.25 \\
\hline \multirow[t]{5}{*}{ (2018 Election) } & MHP & 11.1 & 11.43 & 12.21 \\
\hline & CHP & 22.65 & 24.84 & 21.76 \\
\hline & IYI & 9.96 & 7.12 & 5.87 \\
\hline & HDP & 11.7 & 6.42 & 6.46 \\
\hline & Others & 2.03 & 4.74 & 4.46 \\
\hline
\end{tabular}

${ }^{1}$ Population data is based on 2020 Address Based Population Registration System data provided by the Turkish Statistical Institute.

${ }^{2}$ Sample is weighted for region, gender, and education, based on the population data, using Stata's survwgt command. 


\section{Measurement of key variables}

\subsection{Normative and instrumental system support}

As a guide to identifying measures that tap into all possible forms of support, we began by using Dalton's framework that identifies specific beliefs corresponding to instrumental and normative support for various political object (Dalton 1999: 58). In selecting survey items well-tailored to the Turkish context, we were guided by the need to capture support for the political system in situ not for more democratic alternatives. ${ }^{1}$ Some of the standard survey items, commonly used in comparative surveys of public opinion, carry different connotations in the Turkish context. For example, the direct reference to 'Turkish' identity in the standard World Values Survey (WVS) wording on national pride "How proud are you to be a [citizen of this country]?" is likely to trigger social desirability bias, as nationalism is a value promoted by both the Turkish national education system (Sen 2020) and the current government's propaganda. Additionally criticising Turkishness can lead to prosecution (Tate 2008), suggesting additional incentives for people to avoid answering a question honestly. As such, we avoid the word 'Turkish' in our question wording. Below is a full list of variables used to measure system support in Turkey.

\subsubsection{Normative support}

- The Ottoman Empire period is the most glorious period in Turkish history.

- Is it ever the case that you feel proud in your daily life because of the religion you belong to?

- Is it ever the case that you feel proud in your daily life because of your national identity and the nation you belong to?

- Approval: Strong leader who does not need to bother with the parliament;

- Approval: A political system in which only Turkish nationalist and religious parties are allowed to run in election.

- The government should have the right to ban media organizations that it thinks to be broadcasting against national interests.

- Those who fight against the AKP in fact fight against the Turkish nation and state.

- Only AKP defends the Muslim way of living and Muslims' interests in Turkey.

- Recep Tayyip Erdogan is a political leader with a sense of mission.

- Recep Tayyip Erdogan is an inspiring political leader.

\subsubsection{Instrumental support}

- Turkey is a country that provides high quality life for its citizens.

- Job approval of Recep Tayyip Erdogan

- Job approval of Lutfi Elvan (Minister of Treasury and Finance)

- Policy evaluation: Economy

${ }^{1}$ As already noted, many of the standard survey items commonly used in surveys such as the World Values Survey (WVS) ask about support for democracy in general rather the principles, procedures and structures of each country's political system (see Booth et al. (2009: 11-14) for a discussion) 
- Policy evaluation: Fight against poverty

- Policy evaluation: Internal security

\subsubsection{Exploratory factor analysis of system support items}

Table A.2: Exploratory factor analysis and pairwise correlations for the political support items and government voters

\begin{tabular}{|c|c|c|c|c|c|}
\hline \multirow[b]{2}{*}{ Variable } & \multicolumn{2}{|c|}{ Government voters } & \multicolumn{2}{|c|}{ Non-Government voters } & \multirow{2}{*}{$\begin{array}{c}\text { Corr } \\
\text { Gov. voters }\end{array}$} \\
\hline & Factor1 & Factor2 & Factor1 & Factor2 & \\
\hline \multicolumn{6}{|l|}{ Normative Support } \\
\hline Pride: Nation & 0.46 & 0.62 & 0.27 & 0.74 & 0.36 \\
\hline Pride: Religion & 0.42 & 0.72 & 0.39 & 0.72 & 0.45 \\
\hline Ottoman nostalgia & 0.47 & 0.28 & 0.49 & 0.24 & 0.57 \\
\hline Strong leader & 0.67 & 0.06 & 0.64 & 0.04 & 0.60 \\
\hline Elections limited & 0.57 & 0.28 & 0.51 & 0.43 & 0.57 \\
\hline Restrict media & 0.62 & 0.09 & 0.61 & 0.13 & 0.58 \\
\hline AKP: Support nation & 0.74 & -0.04 & 0.65 & -0.12 & 0.64 \\
\hline AKP: Defend Muslims & 0.74 & -0.06 & 0.74 & -0.12 & 0.65 \\
\hline Erdogan: Mission & 0.83 & -0.06 & 0.64 & -0.14 & 0.62 \\
\hline Erdogan: Inspiring & 0.87 & -0.10 & 0.83 & -0.18 & 0.72 \\
\hline \multicolumn{6}{|l|}{ Instrumental Support } \\
\hline Turkey life quality & 0.77 & -0.16 & 0.74 & -0.07 & 0.60 \\
\hline Success: Econ. Minister & 0.78 & -0.15 & 0.71 & -0.08 & 0.65 \\
\hline Success: Erdogan & 0.88 & -0.09 & 0.86 & -0.14 & 0.73 \\
\hline Policy: Economy & 0.85 & -0.19 & 0.81 & -0.12 & 0.66 \\
\hline Policy: Poverty & 0.83 & -0.21 & 0.82 & -0.14 & 0.64 \\
\hline Policy: Security & 0.75 & -0.14 & 0.69 & -0.10 & 0.62 \\
\hline
\end{tabular}

Note: Only factors that have at least an eigenvalue of 1 are retained. The last column reports the pairwise correlation between government voters in 2018 (vs all else) and each support item. 
Table A.3: Explorative factor analysis and pairwise correlations for ALL political support items and government voters

\begin{tabular}{lccc|ccc|c}
\hline & \multicolumn{3}{c}{ Government voters } & \multicolumn{2}{c}{ Non-Government voters } & Corr \\
Variable & Factor1 & Factor2 & Factor3 & Factor1 & Factor2 & Factor3 & Gov. voters \\
\hline NORMATIVE SUPPORT & & & & & & & \\
Pride: Nation & 0.44 & 0.63 & 0.31 & 0.24 & 0.76 & 0.10 & 0.36 \\
Pride: Religion & 0.38 & 0.69 & 0.21 & 0.38 & 0.68 & 0.00 & 0.45 \\
Ottoman nostalgia & 0.43 & 0.27 & -0.13 & 0.48 & 0.20 & -0.10 & 0.57 \\
Strong leader & 0.65 & 0.12 & -0.30 & 0.62 & 0.06 & -0.23 & 0.60 \\
Elections limited & 0.52 & 0.35 & -0.31 & 0.49 & 0.47 & -0.14 & 0.57 \\
Restrict media & 0.59 & 0.16 & -0.20 & 0.59 & 0.20 & -0.17 & 0.58 \\
AKP: support nation & 0.72 & 0.01 & -0.27 & 0.68 & -0.09 & -0.26 & 0.64 \\
AKP: defend muslims & 0.74 & 0.01 & -0.25 & 0.74 & -0.11 & -0.23 & 0.65 \\
Erdogan: mission & 0.83 & -0.04 & 0.03 & 0.62 & -0.09 & -0.14 & 0.62 \\
Erdogan: inspiring & 0.87 & -0.05 & -0.05 & 0.82 & -0.15 & -0.12 & 0.72 \\
INSTRUMENTAL SUPPORT & & & & & & \\
Turkey life quality & 0.77 & -0.14 & -0.02 & 0.74 & -0.06 & 0.00 & 0.60 \\
Trust: Religious leaders & 0.78 & -0.09 & 0.22 & 0.76 & -0.02 & 0.14 & 0.69 \\
Trust: Elections & 0.69 & -0.22 & 0.38 & 0.53 & -0.27 & 0.39 & 0.57 \\
Trust: Presidency & 0.89 & -0.05 & -0.02 & 0.81 & -0.08 & -0.11 & 0.73 \\
Trust: Parliament & 0.62 & -0.24 & 0.46 & 0.37 & -0.08 & 0.74 & 0.47 \\
Trust: Military & 0.56 & 0.14 & 0.38 & 0.45 & 0.28 & 0.52 & 0.48 \\
Success: econ. Minister & 0.77 & -0.15 & -0.05 & 0.71 & -0.08 & 0.16 & 0.65 \\
Success: Erdogan & 0.87 & -0.04 & -0.08 & 0.85 & -0.13 & -0.07 & 0.73 \\
Policy: economy & 0.85 & -0.15 & -0.05 & 0.79 & -0.12 & -0.03 & 0.66 \\
Policy: poverty & 0.83 & -0.16 & -0.03 & 0.81 & -0.15 & -0.03 & 0.64 \\
Policy: security & 0.76 & -0.09 & -0.01 & 0.69 & -0.07 & 0.19 & 0.62 \\
\hline Note: Only & & & & \\
\end{tabular}

Note: Only factors that have at least an eigenvalue of 1 are retained. The last column reports the pairwise correlation between government voters in 2018 (vs all else) and each support item. 


\subsection{Pro-government behavioral support}

In order to test $\mathrm{H} 2$ and $\mathrm{H} 3$ we use two types of measures to capture behavioral support for the government parties. The first taps into electoral behavior, captured through a voter intention item as well as change in vote from the 2018 election, which is presented in Appendix 9. The second refers to the probability of individuals engaging in pro-government mobilization by joining rallies, campaign contributions, or other forms of pro-government agitation.

Vote intention: Firstly, we will directly ask "How likely are you to vote for one of the parties listed below if the election is held in one week" ( $1=$ Not likely at all; $4=$ undecided; $7=$ certainly).

- I would vote for the AKP or MHP [government parties]

- I would vote for the Nation Alliance (CHP and IYI) [opposition parties]

- I would vote for the HDP [opposition party]

- I would not vote at all.

From this list, we analyze the regime the vote intention for the regime parties, the (combined) average score for the opposition parties and abstention separately.

Election mobilization for the AKP: Voters of the government parties in 2018, additionally saw a battery of questions that relates to election mobilization for the government, including the following items ( $1=$ Not likely at all; $4=$ undecided; $7=$ certainly).

- Joining AKP's election rally

- Encouraging friends and family to vote for the AKP

- Contributing to the AKP's election campaign

We create an index of these three items using the average score.

\subsection{Moderator and control variables}

Government voters: In order to distinguish between voters of the government, the opposition and non-voters, we rely on the vote choice in the 2018 national election, using the following classifications:

- Government voters: AKP, MHP

- Opposition voters: Nation Alliance (CHP and IYI), HDP, Other

- Abstention

Blame attribution: We use a set of four variables on how much respondents blame governmentinternal authorities (Erdogan or the economy minister) versus non-government relevant authorities (the Central Bank or external factors). The variables are based on the following question:

"Some people say that Turkey is having economic troubles recently. To what extent do you think actors listed below are responsible from Turkey's recent economic troubles? $(1=$ Completely responsible, $2=$ significantly responsible, $3=$ somewhat responsible, $4=$ not much responsible, $5=$ not responsible at all) 
- Recep Tayyip Erdogan

- External factors

- Central Bank

- Ministers responsible from the economy

Control variables We ask respondents about their age, gender, education, religiosity, domicile (urban/rural), political interest, partisanship, income, and retrospective economic evaluations. These questions were asked before the treatment. 


\section{Additional analysis: List experiment}

In order to assess whether respondents are truthful about their reported levels of political system support we additional incorporated a list experiment in our survey. Given the authoritarian nature of Turkey, we might expect that respondents may try to hide their true opposition to the regime in fear of repercussions. As we are interested in mapping different types of support in an authoritarian context, we need to understand the level of preference falsification.

The surveys include three list experiments. The sensitive item in each list measures normative support for the community, the regime, and the authorities, focusing on the leader component. The question of the list experiment was included at the start of the survey, before regime support is measured using our question batteries. All respondents participated in all three list experiments. Each time, they were randomly allocated to either the control or treatment conditions.

\subsection{Full list of items used in list experiment}

"Below you will read a group of items. Can you please tell us how many of these items you agree with. You don't need to tell us, which statements you agree with, just how many." [0 to 4/5]

\section{Support for community}

1. Historical mosques should be kept as museums for better protection.

2. It is important to teach national history to next generations.

3. Most of what we learn in schools in terms of the national history is not correct.

4. Historical TV series and movies help people to better understand history.

5. The Ottoman Empire is the most glorious period in Turkish history. [a group of respondents, randomly chosen, will not see this statement]

\section{Support for regime principles}

1. It is important to follow religious norms and ceremonies.

2. Private ownership of business should be increased.

3. Women make equally good political leaders as men.

4. When jobs are scarce, men should have more right to a job than women.

5. The government should have the right to ban media organizations that she thinks to be broadcasting against national interests. [a group of respondents, randomly chosen, will not see this statement]

\section{Support for authority}

1. Generally speaking, most politicians can be trusted.

2. The government is like a parent and should tell us what to do.

3. The government is the employee of the people and should do things according to the wishes of the people.

4. Most politicians work for their own self-interests.

5. Recep Tayyip Erdogan is an inspiring leader. [a group of respondents, randomly chosen, will not see this statement] 
In Figure A.1, you see a graph showing the results of this list experiment 95\% confidence intervals, comparing the direct support for each item (grey bars) and those estimated from the list experiment (white bars). Results are compared across the entire sample as well as government and non-government voters separately. As the variation is smaller in direct questions, confidence intervals are shorter. Results point to a certain level of preference falsification in the sample. We conduct more detailed analysis in Table A.4. 
Figure A.1: Proportion of system support with direct questions versus list experiments

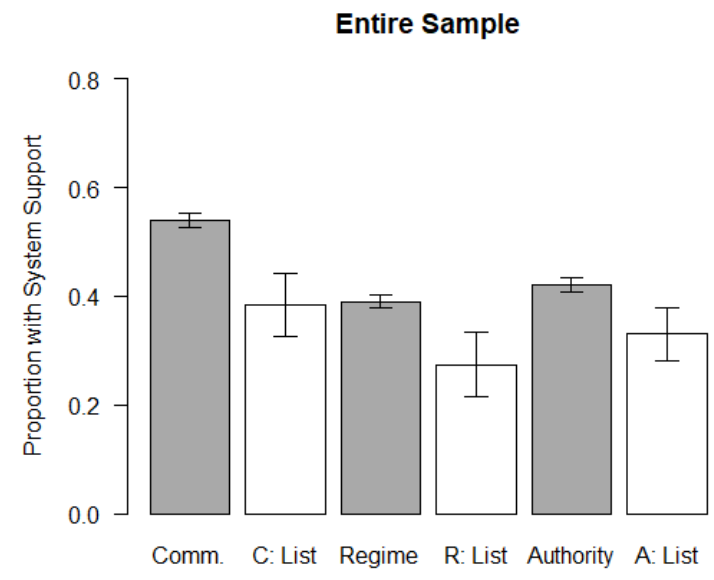

Regime Voters

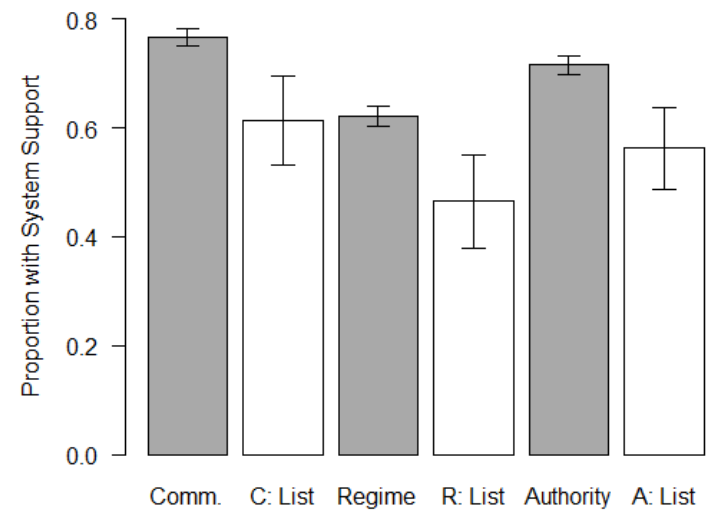

Other Respondents

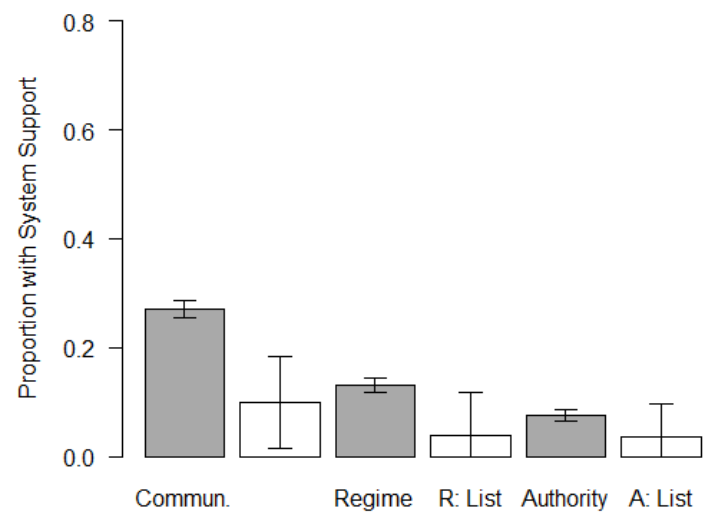

Note: The graph displays proportion of normative support for community, regime, and authority objects. Dark grey columns show proportions with direct questions, white columns show proportions with list experiment questions. Sample includes all participants $(n=6,111)$. Middle category in the direct question is coded as disagreement. 


\subsection{Results of list experiment using different ways to measure middle category}

As we are using a 5-point likert scale to measure observed system support, we have different options on how to create binary, observed support with the three items used in the list experiments. Table A. 4 below, displays three options on how to code the neutral category (=3): 1) Setting neutral (=3) to not agree; 2) setting neutral (=3) to missing; and 3) setting neutral (=3) to agree.

Table A.4: Results list experiment: Normative support for regime objects. \% of respondents agreeing with support item.

\begin{tabular}{lccc}
\hline Variable & All & Gov. voters & Non-gov. voters \\
\hline LIST EXPERIMENT & & & \\
Community: Ottoman nostalgia & $37.14 \%$ & $59.70 \%$ & $9.57 \%$ \\
Regime: Government media ban & $27.79 \%$ & $46.46 \%$ & $4.22 \%$ \\
Authorities: Erdogan inspiring & $33.85 \%$ & $56.08 \%$ & $4.60 \%$ \\
\hline \hline OBSERVED VARIABLES: Setting neutral (=3) to not agree & \\
Community: Ottoman nostalgia & $54.20 \%$ & $77.24 \%$ & $27.07 \%$ \\
Regime: Government media ban & $39.22 \%$ & $62.66 \%$ & $12.42 \%$ \\
Authorities: Erdogan inspiring & $42.32 \%$ & $72.29 \%$ & $7.10 \%$ \\
\hline Rate of preference falsification & & & \\
Community: Ottoman nostalgia & $17.06 \%$ & $17.54 \%$ & $17.50 \%$ \\
Regime: Government media ban & $11.43 \%$ & $16.21 \%$ & $8.20 \%$ \\
Authorities: Erdogan inspiring & $8.47 \%$ & $16.21 \%$ & $2.51 \%$ \\
\hline \hline OBSERVED VARIABLES: Setting neutral (=3) to missing & \\
Community: Ottoman nostalgia & $62.35 \%$ & $87.94 \%$ & $31.87 \%$ \\
Regime: Government media ban & $45.01 \%$ & $75.41 \%$ & $13.87 \%$ \\
Authorities: Erdogan inspiring & $47.25 \%$ & $83.52 \%$ & $7.70 \%$ \\
\hline Rate of preference falsification & & & \\
Community: Ottoman nostalgia & $25.21 \%$ & $28.23 \%$ & $22.30 \%$ \\
Regime: Government media ban & $17.22 \%$ & $28.96 \%$ & $9.65 \%$ \\
Authorities: Erdogan inspiring & $13.41 \%$ & $27.44 \%$ & $3.10 \%$ \\
\hline \hline OBSERVED VARIABLES: Setting neutral (=3) to agree & \\
Community: Ottoman nostalgia & $67.39 \%$ & $89.44 \%$ & $41.60 \%$ \\
Regime: Government media ban & $52.15 \%$ & $79.61 \%$ & $21.05 \%$ \\
Authorities: Erdogan inspiring & $52.59 \%$ & $85.68 \%$ & $13.70 \%$ \\
\hline Rate of preference falsification & & & \\
Community: Ottoman nostalgia & $30.26 \%$ & $29.74 \%$ & $32.04 \%$ \\
Regime: Government media ban & $24.36 \%$ & $33.15 \%$ & $16.83 \%$ \\
Authorities: Erdogan inspiring & $18.74 \%$ & $29.60 \%$ & $9.10 \%$ \\
\hline & & & \\
\hline
\end{tabular}




\section{Balance test}

Table A.5: Balance test of economic priming treatment allocation (ref: control group): Logistic regression

\begin{tabular}{|c|c|c|c|c|c|c|}
\hline \multirow[b]{2}{*}{ Sample } & \multicolumn{3}{|c|}{ SURVEY 1} & \multicolumn{3}{|c|}{ SURVEY 2} \\
\hline & All resp. & Gov voters & Non-gov voters & All resp. & Gov voters & Non-gov voters \\
\hline \multirow[t]{2}{*}{ Age } & -0.002 & -0.007 & -0.001 & -0.003 & -0.001 & -0.002 \\
\hline & [0.004] & {$[0.006]$} & [0.005] & {$[0.002]$} & {$[0.004]$} & {$[0.003]$} \\
\hline \multirow[t]{2}{*}{ Female } & -0.13 & -0.118 & -0.176 & -0.04 & 0.038 & -0.116 \\
\hline & {$[0.110]$} & {$[0.151]$} & {$[0.171]$} & [0.077] & [0.109] & {$[0.114]$} \\
\hline \multicolumn{7}{|c|}{ Education (ref: Primary/secondary) } \\
\hline \multirow[t]{2}{*}{ High school } & 0.012 & -0.038 & 0.086 & 0.059 & 0.065 & 0.069 \\
\hline & {$[0.124]$} & {$[0.160]$} & {$[0.200]$} & {$[0.090]$} & {$[0.124]$} & {$[0.133]$} \\
\hline \multirow[t]{2}{*}{ University } & 0.046 & -0.18 & 0.29 & -0.026 & 0.071 & -0.078 \\
\hline & {$[0.158]$} & {$[0.218]$} & {$[0.240]$} & [0.113] & {$[0.164]$} & {$[0.163]$} \\
\hline \multirow[t]{2}{*}{ Other } & -0.13 & 0.139 & -0.625 & 0.319 & 0.272 & 0.387 \\
\hline & {$[0.466]$} & {$[0.634]$} & {$[0.737]$} & {$[0.253]$} & [0.392] & [0.337] \\
\hline \multirow[t]{2}{*}{ Pol. Interest } & 0.064 & 0.03 & 0.1 & -0.032 & -0.073 & 0.023 \\
\hline & {$[0.067]$} & {$[0.091]$} & [0.106] & [0.049] & [0.069] & {$[0.075]$} \\
\hline \multirow[t]{2}{*}{ Partisan } & 0.059 & -0.071 & 0.233 & 0.03 & -0.153 & 0.117 \\
\hline & {$[0.133]$} & [0.192] & [0.193] & {$[0.090]$} & {$[0.143]$} & {$[0.118]$} \\
\hline \multicolumn{7}{|l|}{ Religious (ref: none) } \\
\hline \multirow[t]{2}{*}{ Not very religious } & 0.119 & 0.459 & 0.033 & -0.086 & -0.243 & -0.152 \\
\hline & {$[0.233]$} & {$[0.931]$} & {$[0.256]$} & {$[0.120]$} & [0.489] & {$[0.134]$} \\
\hline \multirow[t]{2}{*}{ Very religious } & 0.07 & 0.247 & 0.235 & -0.059 & -0.273 & -0.038 \\
\hline & {$[0.229]$} & {$[0.922]$} & {$[0.258]$} & {$[0.118]$} & {$[0.481]$} & {$[0.136]$} \\
\hline \multirow[t]{2}{*}{ Urban } & $0.273 * *$ & 0.252 & 0.269 & 0.045 & -0.108 & 0.164 \\
\hline & {$[0.121]$} & [0.162] & [0.186] & [0.084] & {$[0.121]$} & [0.117] \\
\hline \multirow[t]{2}{*}{ Income } & 0.004 & 0.021 & 0.005 & 0.037 & $0.085 * *$ & 0.012 \\
\hline & {$[0.041]$} & {$[0.060]$} & {$[0.058]$} & {$[0.027]$} & [0.042] & {$[0.036]$} \\
\hline \multirow[t]{2}{*}{ Econ. Eval. } & -0.036 & 0.005 & -0.021 & -0.037 & -0.04 & -0.067 \\
\hline & {$[0.036]$} & {$[0.047]$} & [0.104] & {$[0.026]$} & {$[0.035]$} & {$[0.080]$} \\
\hline \multirow[t]{2}{*}{ Constant } & -0.398 & -0.366 & -0.775 & 0.116 & 0.476 & -0.081 \\
\hline & {$[0.386]$} & {$[1.015]$} & {$[0.558]$} & {$[0.239]$} & {$[0.550]$} & {$[0.366]$} \\
\hline Observations & 1,555 & 885 & 655 & 3,264 & 1,584 & 1,653 \\
\hline
\end{tabular}

Significance levels: $* * * \mathrm{p}<0.01, * * \mathrm{p}<0.05, * \mathrm{p}<0.1$.

Note: The table reports logit regression coefficients and standard errors. 


\section{Full results of Figures 3 to 5}

Table A.6: Full results Figure 3

\begin{tabular}{lcccc}
\hline Sample: & \multicolumn{2}{c}{ Government voters } & \multicolumn{2}{c}{ Non-government voters } \\
Outcome: Support & Normative & Instrumental & Normative & Instrumental \\
\hline Treatment & -0.207 & $-3.148^{* *}$ & -0.210 & -1.001 \\
& {$[1.391]$} & {$[1.512]$} & {$[1.618]$} & {$[1.401]$} \\
Constant & $72.032^{* * *}$ & $61.024 * * *$ & $29.465^{* * *}$ & $17.292^{* * *}$ \\
& {$[0.959]$} & {$[1.042]$} & {$[1.157]$} & {$[1.003]$} \\
\hline Observations & 1,126 & 1,122 & 871 & 866 \\
$\mathrm{R}^{2}$ & 0.000 & 0.004 & 0.000 & 0.001 \\
\hline
\end{tabular}

Significance levels: $* * * \mathrm{p}<0.01, * * \mathrm{p}<0.05, * \mathrm{p}<0.1$.

Note: The table reports linear regression coefficients and standard errors. The results are based on survey 1 .

Table A.7: Full results Figure 4

\begin{tabular}{|c|c|c|c|c|c|}
\hline \multirow[t]{2}{*}{ Outcome: } & \multicolumn{4}{|c|}{ Vote for... } & \multirow{2}{*}{$\begin{array}{l}\text { Mobilize } \\
\text { for AKP }\end{array}$} \\
\hline & $\mathrm{AKP}+\mathrm{MHP}$ & Abstain & Nat. Alliance & HDP & \\
\hline \multicolumn{6}{|c|}{ Sample: GOVERNMENT VOTERS } \\
\hline \multirow[t]{2}{*}{ Treatment } & $-0.342 * * *$ & 0.008 & $0.215 * *$ & 0.006 & $-0.291 * *$ \\
\hline & {$[0.106]$} & {$[0.150]$} & {$[0.107]$} & {$[0.060]$} & {$[0.144]$} \\
\hline \multirow[t]{2}{*}{ Income } & $0.066 *$ & $-0.092 *$ & -0.05 & -0.035 & -0.069 \\
\hline & {$[0.039]$} & {$[0.055]$} & {$[0.039]$} & {$[0.022]$} & {$[0.053]$} \\
\hline \multirow[t]{2}{*}{ Constant } & $5.591 * * *$ & $4.556 * * *$ & $2.129 * * *$ & $1.377 * * *$ & $5.205^{* * *}$ \\
\hline & {$[0.135]$} & {$[0.189]$} & {$[0.136]$} & {$[0.077]$} & {$[0.184]$} \\
\hline Observations & 1,627 & 1,291 & 1,449 & 1,469 & 1,102 \\
\hline $\mathrm{R}^{2}$ & 0.008 & 0.002 & 0.004 & 0.002 & 0.005 \\
\hline \multicolumn{6}{|c|}{ Sample: NON-GOVERNMENT VOTERS } \\
\hline \multirow[t]{2}{*}{ Treatment } & -0.071 & 0.007 & 0.117 & -0.199 & \\
\hline & {$[0.073]$} & {$[0.134]$} & {$[0.111]$} & {$[0.125]$} & \\
\hline \multirow[t]{2}{*}{ Constant } & $1.571 * * *$ & $3.885 * * *$ & $5.389 * * *$ & $2.592 * * *$ & \\
\hline & {$[0.051]$} & {$[0.094]$} & {$[0.079]$} & {$[0.086]$} & \\
\hline Observations & 1,725 & 1,693 & 1,689 & 1,429 & \\
\hline $\mathrm{R}^{2}$ & 0.001 & 0.000 & 0.001 & 0.002 & \\
\hline
\end{tabular}

Significance levels: $* * * \mathrm{p}<0.01, * * \mathrm{p}<0.05, * \mathrm{p}<0.1$.

Note: Government voters only. The table reports linear regression coefficients and standard errors. The results are based on survey 2. Income is included as there is an imbalance between treatment and control group for the sub-sample of government voters used in these analyses. See Table A.5. 
Table A.8: Full results Figure 5

\begin{tabular}{lcc}
\hline & $\mathrm{M} 1$ & $\mathrm{M} 2$ \\
\hline Treatment & $-1.183 * * *$ & $-0.907 * * *$ \\
& {$[0.258]$} & {$[0.196]$} \\
Normative support & $0.056^{* * *}$ & \\
& {$[0.002]$} & \\
Treatment x Normative & $0.013 * * *$ & \\
& {$[0.003]$} & \\
Instrumental & & $0.053 * * *$ \\
& & {$[0.002]$} \\
Treatment x Instrumental & & $0.012 * * *$ \\
& & {$[0.003]$} \\
Income & $0.119 * * *$ & 0.022 \\
& {$[0.029]$} & {$[0.028]$} \\
Constant & $1.344 * * *$ & $2.402 * * *$ \\
& {$[0.207]$} & {$[0.163]$} \\
\hline Observations & 1627 & 1626 \\
$\mathrm{R}^{2}$ & 0.463 & 0.504 \\
\hline
\end{tabular}

Significance levels: $* * * \mathrm{p}<0.01, * * \mathrm{p}<0.05, * \mathrm{p}<0.1$.

Note: Outcome: Vote for AKP+MHP. Government voters only. The table reports linear regression coefficients and standard errors. The results are based on survey 2 . Income is included as there is an imbalance between treatment and control group for the sub-sample of government voters used in these analyses. See Table A.5. 


\section{Additional results H1 (Fig 3): Single survey items for regime support}

Figure A.2: Impact of crisis treatment on autocratic system support: Regression coefficients and 95\% confidence intervals. Sample: Government voters
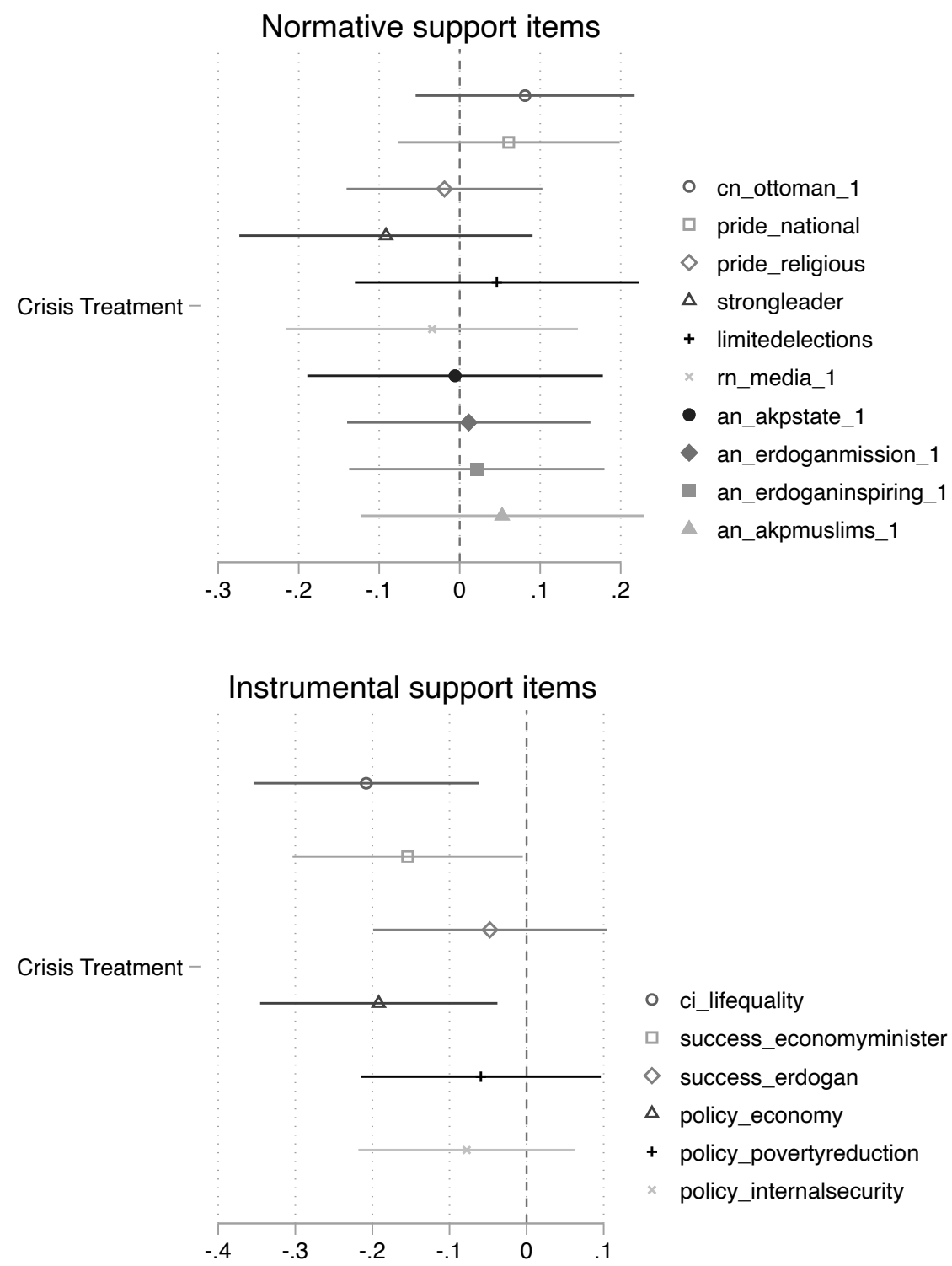

Note: The graph displays the regression coefficient of the economic crisis treatment on regime support - outcome variables. All support variables range from from 1 - no support to 5 - complete support. The results are based on survey 1, in which the regime support variables were asked after the introduction of the economic treatment. The analysis are based on linear regression models with no control variables. 


\section{Additional results H2 (Fig 4): Vote change variable as outcome}

We further create a categorical variable for vote change, combining the responses to a question on how respondents voted in the 2018 election and their vote intention now, as follows:

Table A.9: Measuring vote switching

\begin{tabular}{lllr}
\hline Vote 2018 & Vote intention now & Vote change & \% of obs. \\
\hline AKP or MHP & AKP or MHP - score 6/7 & Loyal gov. voters & 69.3 \\
AKP or MHP & AKP or MHP - score 3-5 & Fleeting gov. voters & 16.7 \\
AKP or MHP & AKP or MHP - score 1/2 Opposition - score 6/7 & Defectors to opposition & 4.0 \\
AKP or MHP & AKP or MHP - score 1/2 Abstention - score 6/7 & Exit of previous gov. voters & 4.7 \\
Abstention & AKP or MHP - score 6/7 & Gov. mobilization - non-voters & 2.5 \\
Opposition & AKP or MHP - score 6/7 & Gov. mobilization - opposition & 2.8 \\
\hline
\end{tabular}

Table A.10: Multinominal logistic regression of change in vote, baseline = loyal government voters

\begin{tabular}{lcccc}
\hline & Coef. & s.e. & \multicolumn{2}{c}{$95 \%$ conf. Intervals } \\
\hline Fleeting gov. voter & & & & \\
Treatment & 0.176 & 0.140 & -0.099 & 0.451 \\
Intercept & -1.655 & 0.100 & -1.850 & -1.460 \\
& & & & \\
Defecting gov. voter & & & & \\
Treatment & $0.553^{* *}$ & 0.235 & 0.093 & 1.013 \\
Intercept & -2.977 & 0.181 & -3.332 & -2.622 \\
Exiting gov. voter & & & & \\
Treatment & & & & \\
Intercept & 0.252 & 0.213 & -0.164 & 0.669 \\
& -2.636 & 0.154 & -2.938 & -2.333 \\
New gov. voter from abs. & & & & \\
Treatment & -0.311 & 0.293 & -0.885 & 0.263 \\
Intercept & -3.009 & 0.184 & -3.369 & -2.648 \\
& & & & \\
New gov. voter from opp. & & & & \\
Treatment & 0.229 & 0.267 & -0.295 & 0.753 \\
Intercept & -3.110 & 0.193 & -3.489 & -2.732 \\
\hline
\end{tabular}

Significance levels: $* * * \mathrm{p}<0.01, * * \mathrm{p}<0.05, * \mathrm{p}<0.1$.

Note: The table reports logit regression coefficients and standard errors. The results are based on survey 2 , in which the regime support variables were asked before the introduction of the economic treatment. Number of observations $=1,714$. 


\section{Additional results for $\mathrm{H3a}+\mathrm{b}$ (Fig 5): Single survey items for pro-government behavioural support: Interaction between treatment and system support}

Figure A.3: Impact of crisis treatment on likelihood to vote for government parties. Marginal effects and $95 \%$ confidence intervals. Sample: Government voters

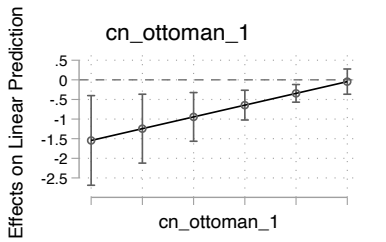

cn_ottoman_1
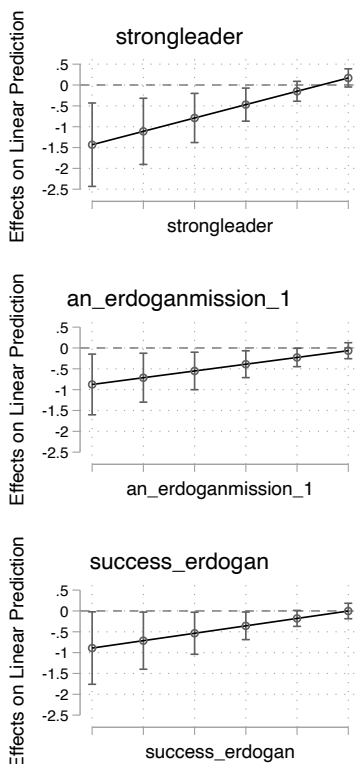

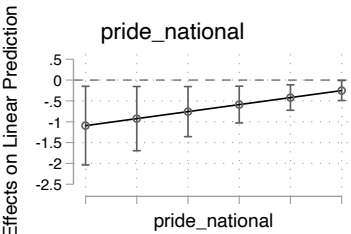

limitedelections
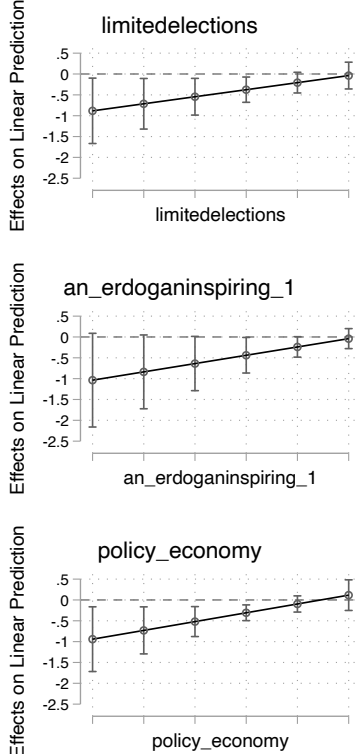
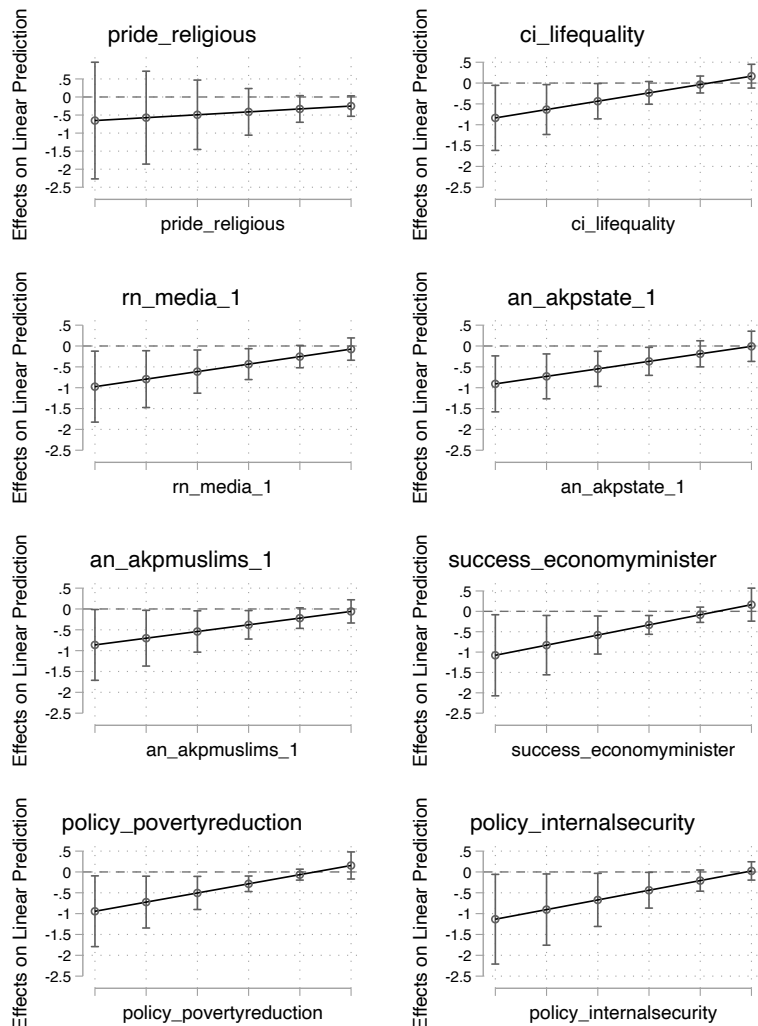
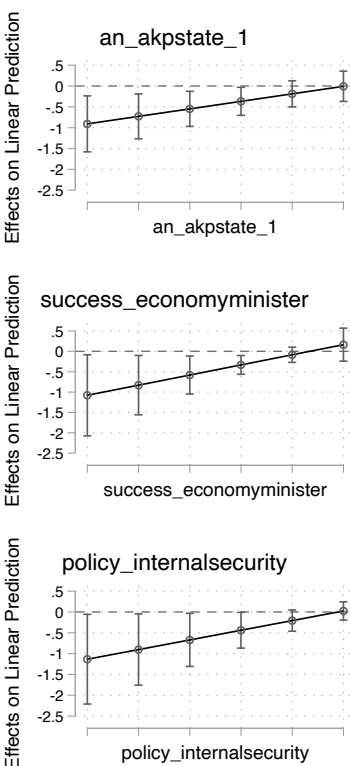

Note: The graph displays the marginal effect of the economic crisis treatment. Outcome ranges from from 1 - not likely at all to 7 - very certain. All items range from 1 (no support) to 5 (high support). The results are based on survey 2 , in which the regime support variables were asked before the introduction of the economic treatment. The analysis are based on linear regression models, controlling for income. 


\section{Additional results for $\mathrm{H3a}+\mathrm{b}$ (Fig 5): Conditional of economic treatment on mobilization for AKP by of system support}

Figure A.4: Impact of crisis treatment on likelihood to mobilize for AKP. Marginal effects and 95\% confidence intervals. Sample: Government voters
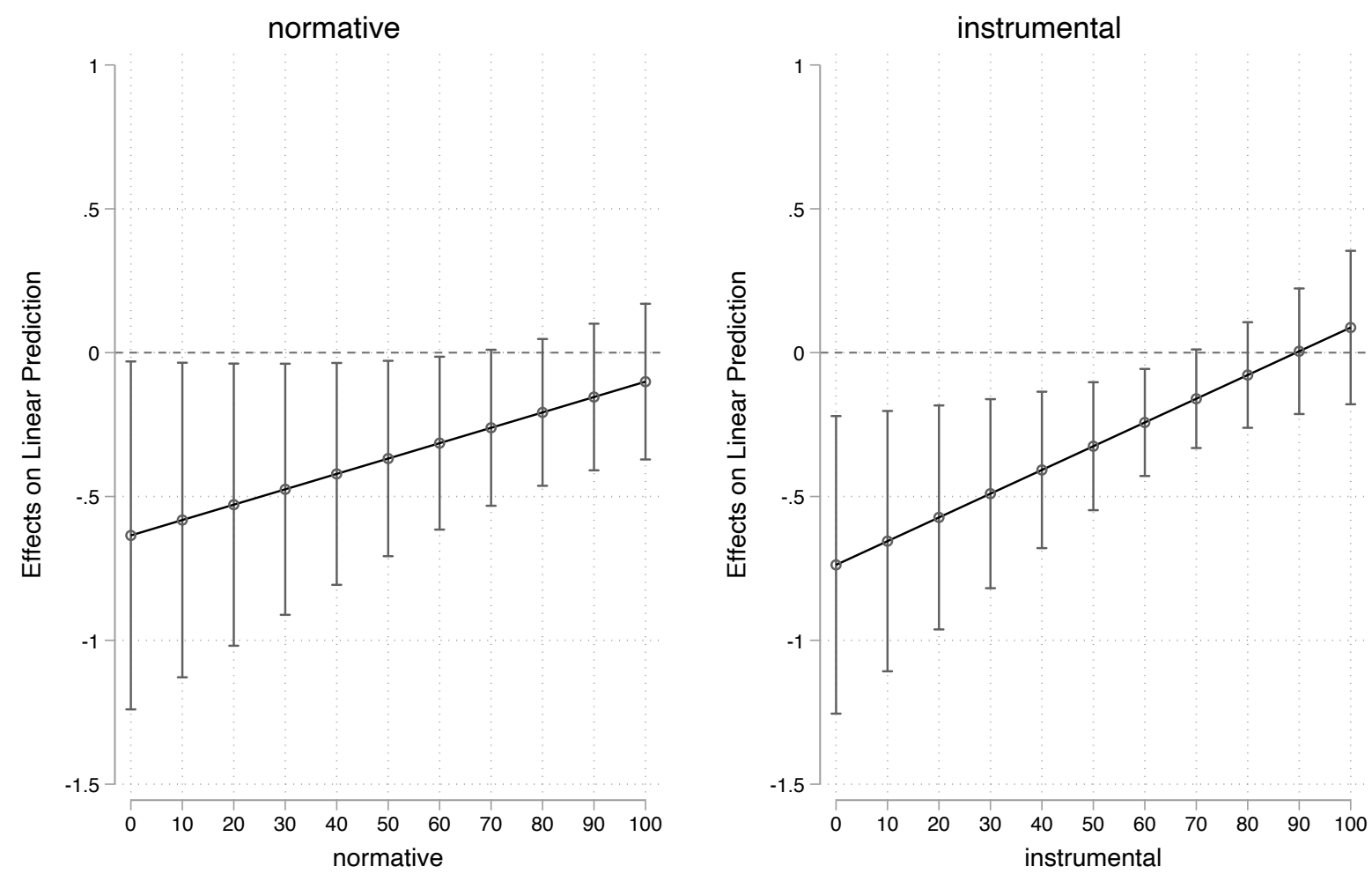

Note: The graph displays the marginal effects of the economic crisis treatment. The outcome ranges from 1 - not likely at all to 7 - very certain. The results are based on survey 2 , in which the regime support variables were asked before the introduction of the economic treatment. The analysis are based on linear regression models, controlling for income. 


\section{Mechanisms behind the lack of defection: Blame attributions}

To better understand why respondents with high system support do not react to the economic treatment, we explore how blame assignment mediates the relationship between the crisis treatment and the likelihood to vote for the regime.

In our survey, we asked to what extent they put the blame for Turkey's economic troubles on four actors: Erdogan, economy ministers, central bank, and external factors. As discussed in the article, Erdogan is at the center of Turkey's current political system. The relationship between Central Bank and the political system is more ambiguous: the Central Bank is legally independent from the regime, but in practice it is just another institution that Erdogan has full control over. Economy ministers are also regime actors, but they are not as central to the regime as Erdogan is. Between 2020 and 2022, three different people worked as the minister of treasury, for example. Finally, putting the blame on external factors is, by definition, a way to avoid blaming the government for national economic troubles.

We will start our analyses with normative support, as our preregistration plan specifically referred to this analysis for the normative support variable. We will then repeat the entire analysis for instrumental support variable.

\subsection{Blame assignment and normative support}

First, we explore whether the effect of the crisis treatment on blame assigned to these actors vary, depending on the existing levels of normative support. Figure A.5 presents how levels of normative support conditions the effect of the crisis treatment on blame assignment.

As can be seen in Figure A.5, effects of the crisis treatment on blame assignments to economy ministers and the central bank are not moderated by the existing levels of normative support. This is not surprising, given that these actors are neither as central to the system as "Erdogan," nor as external to it as "external factors." For "blame assigned to Erdogan" and "blame assigned to external factors," on the other hand, we see more meaningful changes. Government voters that have lower levels of normative support, i.e. between 0/100 and 50/100, increase the blame assigned to Erdogan, when they are exposed to the crisis treatment $(p<0.10)$. These voters also decrease the blame assigned to external factors $(p<0.10)$. To the contrary, government voters with highest levels of normative support, i.e. normative support over 90/100, increase the blame they assign to external factors.

Having shown that the impact of the crisis treatment on blame attribution to Erdogan and external factors depend on existing levels of normative support, we explore whether these two variables' indirect effect, mediating the relationship between the crisis treatment and the likelihood to vote for the regime parties, varies across voters with higher and lower levels of normative support. Our mediation analyses follow the method developed by Imai et al. (2011) and we use mediation package for Stata developed by Hicks and Tingley (2011). To simplify the interpretation of results from this moderated mediation analysis, we divide our sample into two equally sized groups of regime voters, based on their levels of normative system support: regime voters with lower normative support (lower than 77.5/100) and regime voters with higher normative support (higher than 77.5/100).

First, Table A.11 present results for blame assignment to Erdogan. Results are strikingly different across these two groups of government voters. For regime voters with lower normative support, blame assignment to Erdogan significantly mediates $45 \%$ of the relationship between the crisis treatment likelihood to vote for the regime. When these voters are exposed to the crisis treatment, they make Erdogan responsible for the economic troubles, and they become less likely to vote for the regime. For regime voters with higher levels of normative support, on the other hand, the indirect 
Figure A.5: Interaction between economic crisis treatment and normative support on blame assigned for poor economic performance. Marginal effects and 95\% confidence intervals. Sample: Government voters
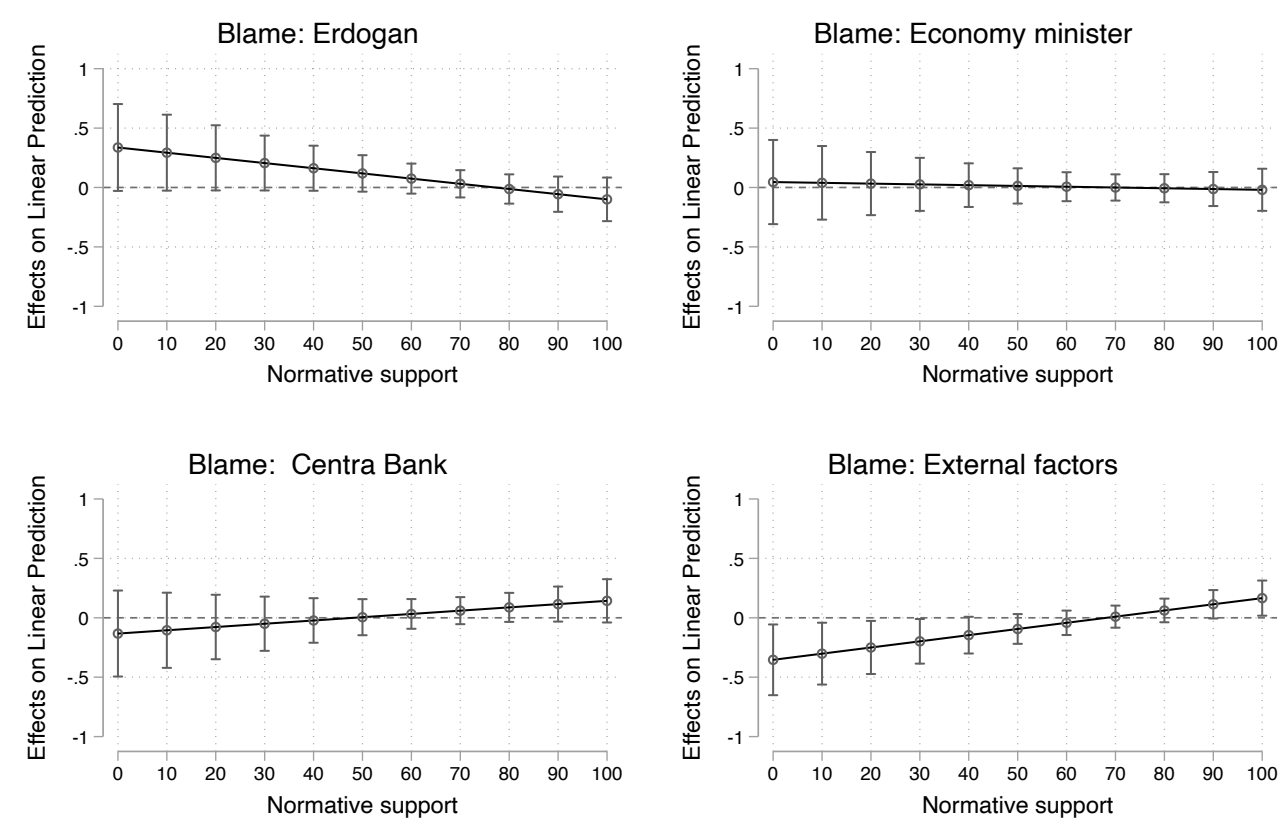

Note: The graph displays the marginal effect of the economic crisis treatment. Outcome ranges from 1 - no blame at all to 5 - complete blame. The results are based on survey 2 , in which the system support variables were asked before the introduction of the economic treatment. The analysis are based on linear regression models, controlling for income.

effect is not significant.

Second, Table A.12 present results for blame assignment to external factors. The results again vary across government voters with higher and lower levels of normative support. For government voters with lower levels of normative support, we do not see a mediation effect occurring through blame assigned to external factors. For government voters with higher levels of normative support, on the other hand, we note a small but positive mediation effect. When exposed to the crisis treatment, voters with higher levels of normative support increase the blame assigned to external factors, and they become even more likely to vote for regime parties. The increased likelihood to vote for the regime might be seen as a backlash effect, emerging in survey context. Still, Table A.12 and Figure A.5 clearly demonstrate that, when they are exposed to economic troubles, voters with higher levels of normative support shift the blame to external factors.

To sum up, our analysis reveals a complex relationship between normative support, economic crisis, and blame assignments. When faced with economic troubles, government voters with lower levels of normative support keep Erdogan responsible for the crisis. This decreases their likelihood to vote for the regime parties. For government voters with higher levels of normative support, on the other hand, blame assigned to external factors play a more decisive role. When faced with economic troubles, these voters attribute the blame to external factors and they become even more likely to vote for the regime. 
Table A.11: Mediation analysis: Blame attribution to Erdogan and economic crisis treatment on vote for governing parties among regime voters

\begin{tabular}{llll}
\hline \multicolumn{1}{c}{ Sample: LOW NORMATIVE SUPPORT } & Mean & $95 \%$ Confidence Interval \\
\hline $\begin{array}{l}\text { ACME } \\
\text { Treatment } \rightarrow \text { Blame to Erdogan } \rightarrow \text { Vote for Gov. }\end{array}$ & -0.253 & -0.470 & -0.043 \\
$\begin{array}{l}\text { Direct Effect } \\
\text { Treatment } \rightarrow \text { Likelihood to Vote for Gov. }\end{array}$ & -0.308 & -0.600 & -0.002 \\
$\begin{array}{l}\text { Total Effect } \\
\text { Treatment } \rightarrow \text { Likelihood to Vote for Gov. }\end{array}$ & -0.560 & -0.921 & -0.195 \\
$\begin{array}{l}\text { Proportion of total effect mediated } \\
\quad \text { Sample: HIGH NORMATIVE SUPPORT }\end{array}$ & 0.449 & 0.273 & 1.271 \\
\hline $\begin{array}{l}\text { ACME } \\
\text { Treatment } \rightarrow \text { Blame to Erdogan } \rightarrow \text { Vote for Gov. }\end{array}$ & 0.015 & -0.005 & 0.039 \\
$\begin{array}{l}\text { Direct Effect } \\
\text { Treatment } \rightarrow \text { Likelihood to Vote for Gov. }\end{array}$ & 0.019 & -0.124 & 0.168 \\
$\begin{array}{l}\text { Total Effect } \\
\text { Treatment } \rightarrow \text { Likelihood to Vote for Gov. }\end{array}$ & 0.034 & -0.111 & 0.184 \\
Proportion of total effect mediated & 0.149 & -1.868 & 2.81 \\
\hline
\end{tabular}

Government voters only, using survey 2. Analysis was conducted in Stata 17 using mediation package (Hicks and Tingley 2011).

\subsection{Blame assignment and instrumental support}

We will now replicate the analysis above for instrumental support variable. First, we explore whether the effect of the crisis treatment on blame assigned to to these actors vary, depending on the existing levels of instrumental support. Figure A.6 presents how levels of instrumental support conditions the effect of the crisis treatment on blame assignment.

Most interesting result in Figure A.6 is that, unlike the effect of normative support variable in Figure A.5, we do not see a moderating effect of instrumental support variable on blame assigned to Erdogan. Regime voters having lower levels of instrumental support do not put the blame for economic troubles on Erdogan. We still see, however, moderated effects on blame assigned to external factors.

Next, we split our sample into two equally sized groups of government voters: government voters with higher instrumental support (instrumental $\left.{ }_{6} 65\right)$ and government voters with lower instrumental support (instrumental ${ }_{i} 65$ ). First we conduct a mediation analysis, exploring whether blame assigned to Erdogan mediates a causal effect between the crisis treatment and the likelihood to vote for the regime and whether these effects vary across levels of instrumental support. As documented in Table A.13, we do not find any mediation effects across any of these voter groups.

Second, Table A.14 present results for blame assignment to external factors. The result is same here with Table A.13: no significant mediation effect across any of the voter groups. 
Table A.12: Mediation analysis: Blame attribution to external factors and economic crisis treatment on vote for governing parties among regime voters

\begin{tabular}{|c|c|c|c|}
\hline & Mean & \multicolumn{2}{|c|}{$95 \%$ Confidence Interval } \\
\hline \multicolumn{4}{|l|}{ ACME } \\
\hline Treatment $\rightarrow$ Blame to external factors $\rightarrow$ Vote for Gov. & -0.071 & -0.216 & 0.069 \\
\hline \multicolumn{4}{|l|}{ Direct Effect } \\
\hline Treatment $\rightarrow$ Likelihood to Vote for Gov. & -0.435 & -0.752 & -0.105 \\
\hline \multicolumn{4}{|l|}{ Total Effect } \\
\hline Treatment $\rightarrow$ Likelihood to Vote for Gov. & -0.506 & -0.867 & -0.146 \\
\hline Proportion of total effect mediated & 0.140 & 0.081 & 0.452 \\
\hline \multicolumn{4}{|l|}{ Sample: HIGH NORMATIVE SUPPORT } \\
\hline $\begin{array}{l}\text { ACME } \\
\text { Treatment } \rightarrow \text { Blame to external factors } \rightarrow \text { Vote for Gov. }\end{array}$ & 0.019 & 0.001 & 0.045 \\
\hline \multicolumn{4}{|l|}{ Direct Effect } \\
\hline Treatment $\rightarrow$ Likelihood to Vote for Gov. & 0.042 & -0.103 & 0.193 \\
\hline \multicolumn{4}{|l|}{ Total Effect } \\
\hline Treatment $\rightarrow$ Likelihood to Vote for Gov. & 0.061 & -0.086 & 0.215 \\
\hline Proportion of total effect mediated & 0.186 & -2.153 & 2.704 \\
\hline
\end{tabular}

Government voters only, using survey 2. Analysis was conducted in Stata 17 using mediation package (Hicks and Tingley 2011). 
Figure A.6: Interaction between economic crisis treatment and normative support on blame assigned for poor economic performance. Marginal effects and 95\% confidence intervals. Sample: Government voters
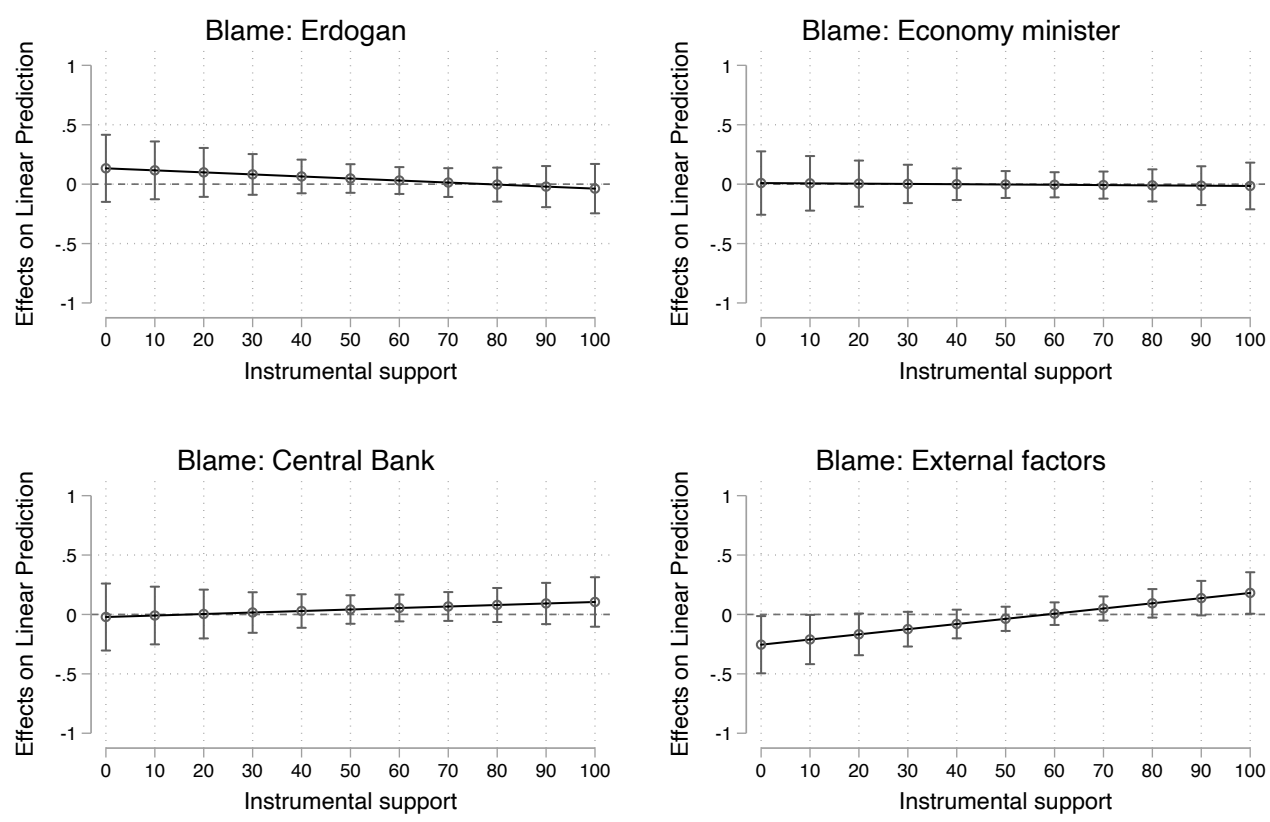

Note: The graph displays the marginal effect of the economic crisis treatment. Outcome ranges from 1 - no blame at all to 5 - complete blame. The results are based on survey 2 , in which the system support variables were asked before the introduction of the economic treatment. The analysis are based on linear regression models, controlling for income. 
Table A.13: Mediation analysis: Blame attribution to Erdogan and economic crisis treatment on likelihood to vote for governing parties among regime voters

\begin{tabular}{lccc}
\hline \multicolumn{1}{c}{ Sample: LOW INSTRUMENTAL SUPPORT } & Mean & \multicolumn{1}{c}{$95 \%$ Confidence Interval } \\
\hline $\begin{array}{l}\text { ACME } \\
\text { Treatment } \rightarrow \text { Blame to Erdogan } \rightarrow \text { Vote for Gov. }\end{array}$ & -0.1831015 & -0.3854505 & 0.0116422 \\
$\begin{array}{l}\text { Direct Effect } \\
\text { Treatment } \rightarrow \text { Likelihood to Vote for Gov. }\end{array}$ & -.3906321 & -.6904821 & -.0775461 \\
$\begin{array}{l}\text { Total Effect } \\
\text { Treatment } \rightarrow \text { Likelihood to Vote for Gov. }\end{array}$ & -0.5737336 & -0.9269193 & -0.2106887 \\
Proportion of total effect mediated & 0.3176645 & 0.1961746 & 0.8631918 \\
\hline \multicolumn{1}{c}{ Sample: HIGH INSTRUMENTAL SUPPORT } & & \\
$\begin{array}{l}\text { ACME } \\
\text { Treatment } \rightarrow \text { Blame to Erdogan } \rightarrow \text { Vote for Gov. }\end{array}$ & 0.0076019 & -0.0112949 & 0.0277218 \\
$\begin{array}{l}\text { Direct Effect } \\
\text { Treatment } \rightarrow \text { Likelihood to Vote for Gov. }\end{array}$ & & & \\
Total Effect \\
$\begin{array}{l}\text { Treatment } \rightarrow \text { Likelihood to Vote for Gov. } \\
\text { Proportion of total effect mediated }\end{array}$ & 0.0900524 & -0.0312495 & 0.2167088 \\
\hline
\end{tabular}

Government voters only, using survey 2. Analysis was conducted in Stata 17 using mediation package (Hicks and Tingley 2011). 
Table A.14: Mediation analysis: Blame attribution to external factors and economic crisis treatment on vote for governing parties among regime voters

\begin{tabular}{|c|c|c|c|}
\hline & Mean & \multicolumn{2}{|c|}{$95 \%$ Confidence Interval } \\
\hline \multicolumn{4}{|l|}{ ACME } \\
\hline Treatment $\rightarrow$ Blame to external factors $\rightarrow$ Vote for Gov. & -0.016 & -0.152 & 0.120 \\
\hline \multicolumn{4}{|l|}{ Direct Effect } \\
\hline Treatment $\rightarrow$ Likelihood to Vote for Gov. & -0.519 & -0.835 & -0.189 \\
\hline \multicolumn{4}{|l|}{ Total Effect } \\
\hline Treatment $\rightarrow$ Likelihood to Vote for Gov. & -0.535 & -0.895 & -0.172 \\
\hline Proportion of total effect mediated & 0.029 & 0.018 & 0.083 \\
\hline \multicolumn{4}{|l|}{ Sample: HIGH INSTRUMENTAL SUPPORT } \\
\hline $\begin{array}{l}\text { ACME } \\
\text { Treatment } \rightarrow \text { Blame to external factors } \rightarrow \text { Vote for Gov. }\end{array}$ & 0.006 & -0.010 & 0.026 \\
\hline \multicolumn{4}{|l|}{ Direct Effect } \\
\hline Treatment $\rightarrow$ Likelihood to Vote for Gov. & 0.104 & -0.015 & 0.227 \\
\hline \multicolumn{4}{|l|}{ Total Effect } \\
\hline Treatment $\rightarrow$ Likelihood to Vote for Gov. & 0.110 & -0.010 & 0.237 \\
\hline Proportion of total effect mediated & 0.053 & -0.266 & 0.438 \\
\hline
\end{tabular}

Government voters only, using survey 2. Analysis was conducted in Stata 17 using mediation package (Hicks and Tingley 2011). 


\section{Robustness tests dropping pride items from normative index}

In this section, we replicate the main results testing $\mathrm{H} 1$ and $\mathrm{H} 2$ using an alternative measure for normative support. Given that two items measuring religious and national pride load on a separate dimension (see Table A.2), we use an alternative measure for normative support that drops these two items.

As Figure A.7 confirms, normative support remains unmoved by the crisis treatment even after removing these two items from the measure. Figure A.8 further confirms the observed conditional effect of normative support to moderate the impact of the crisis treatment on the behavioral intention to support the governing parties in an upcoming election.

Figure A.7: H1 - Impact of treatment on alternative normative support measure: Regression coefficients and $95 \%$ confidence intervals.

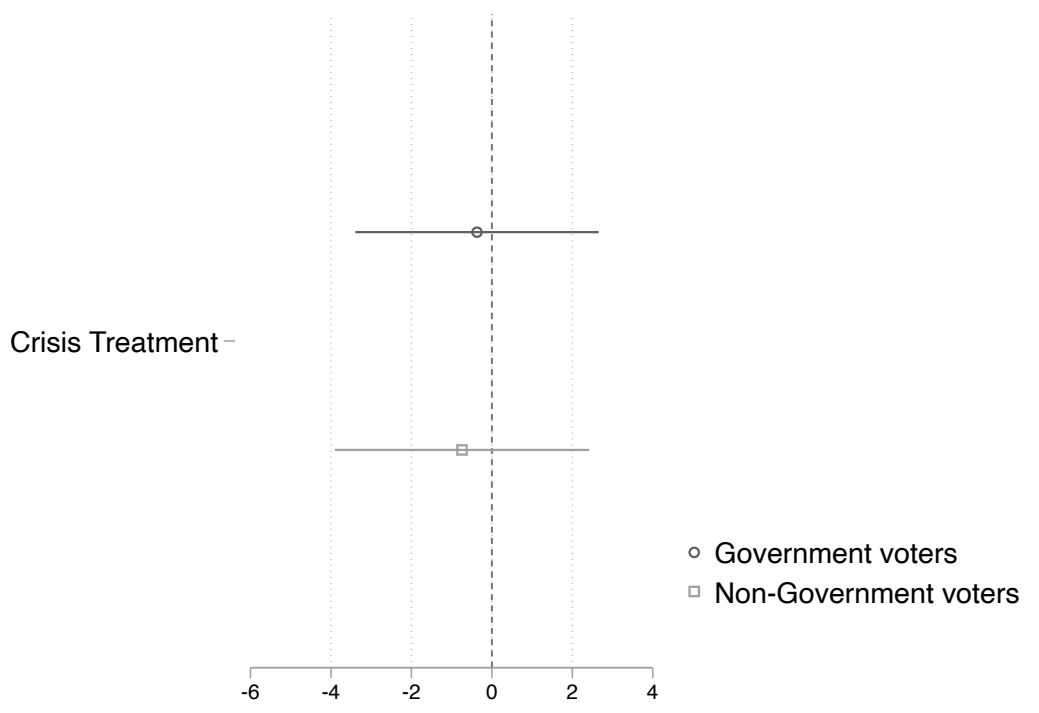

Note: The graph displays the regression coefficient of the economic crisis treatment on normative support, which ranges from from 0 - no support to 100 - complete support. The results are based on survey 1 . The analysis are based on linear regression models with no control variables. 
Figure A.8: H3a: Interaction between economic crisis treatment and alternative normative support on likelihood to vote for government parties. Marginal effects and 95\% confidence intervals. Sample: Government voters

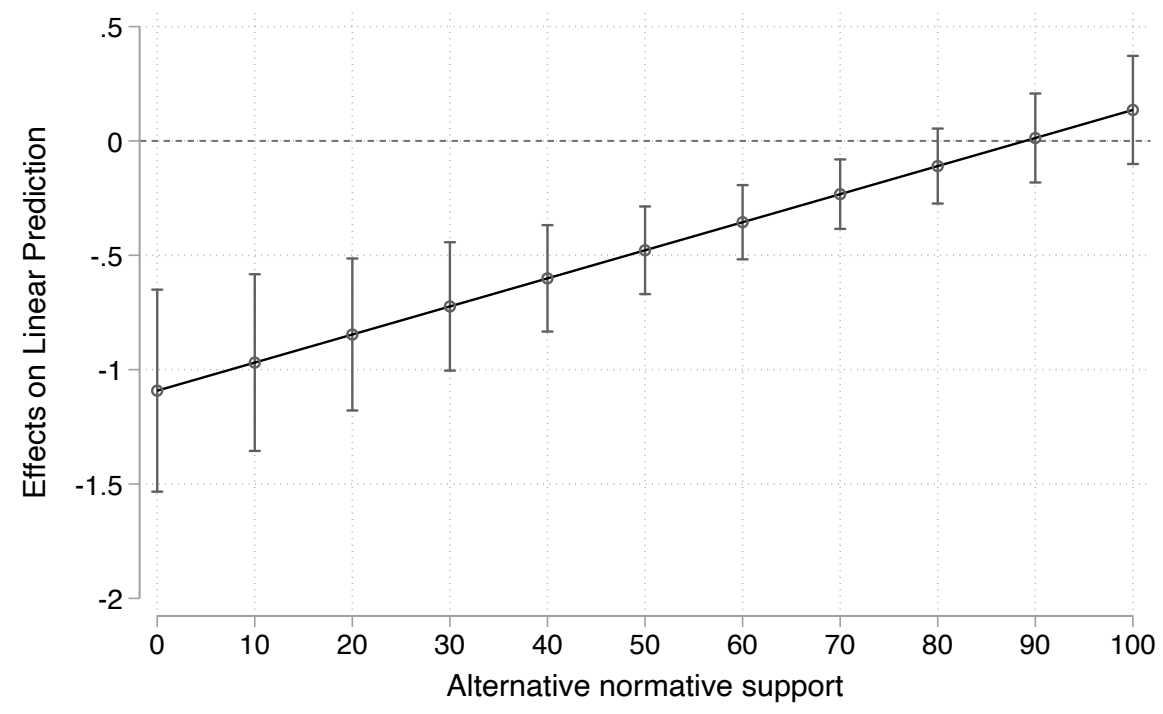

Note: The graph displays the marginal effect of the economic crisis treatment. Outcome ranges from 1 - not likely at all to 7 - very certain. The results are based on survey 2 . The analysis are based on linear regression models, controlling for income. 


\section{Treatment effects on economic assessments}

In order to test the validity of the treatment, we estimated the impact of the priming experiment on the change in the retrospective economic evaluations, which was asked pre- and post-treatment. The change variable can range from -4 (updated economic evaluation negatively) to +4 (updated economic evaluation positively). If our treatment is effective, we would expect that respondents evaluate the economic situation in Turkey more negatively after being exposed to the treatment. Figure A.9 reports the impact of the treatment (compared to the control group) for four samples: 1) all respondents, 2) government voters (AKP+MHP), 3) opposition voters (Nation Alliance of CHP and IYI, HDP, Other), and 4) non-voters. To classify voters we use the 2018 parliamentary election. As the figure shows, the crisis treatment has a strong and significant effect for government voters who after being exposed to the treatment evaluate the economy more negatively. The effect is significant, but significantly smaller for opposition voters. The treatment does not move the economic evaluation of non-voters, which could be driven by a floor effect, as pre-treatment economic evaluations are already very low for these groups. ${ }^{2}$

Figure A.9: Change in pre- and post-treatment economic evaluations for four different samples

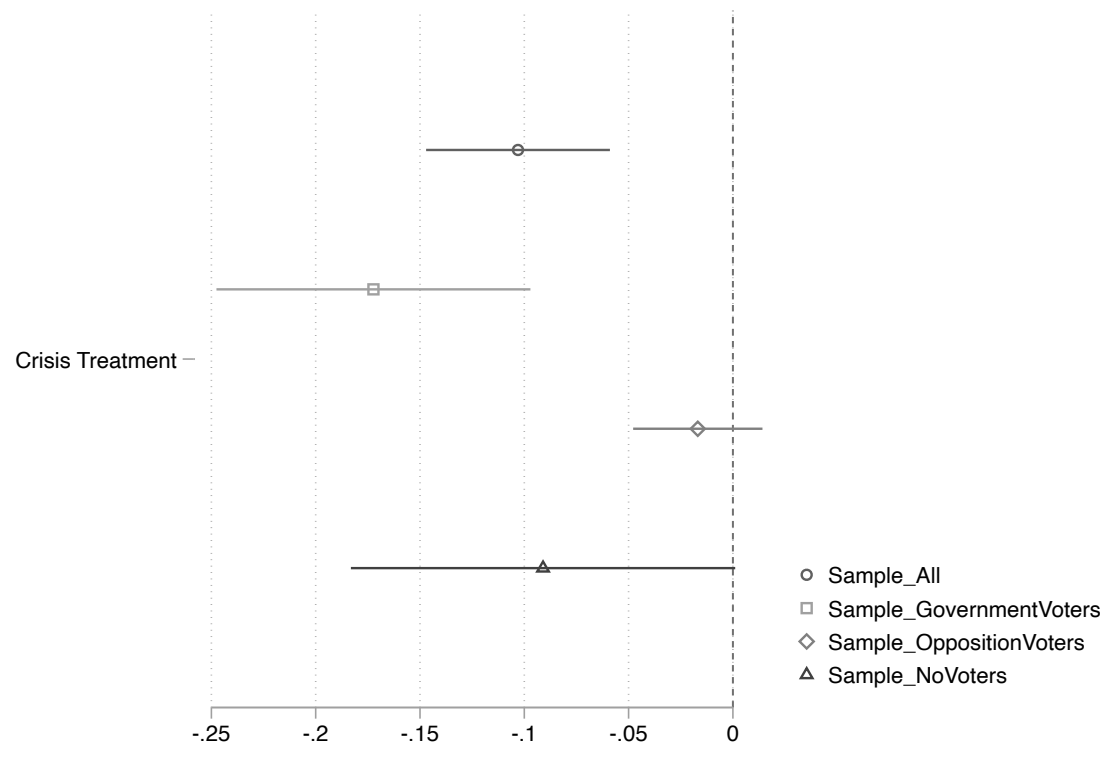

Note: The graph displays the regression coefficient of the economic crisis treatment on the pre-post-treatment change in economic evaluations.

\footnotetext{
${ }^{2}$ On a 1 to 5 scale, government voters evaluate the economy pre-treatment on average as 2.96 , while the average value for opposition voters is 1.15 and 1.48 for non-voters.
} 


\section{Perceptual screen of regime support on economic evaluations}

To test the mechanism that regime support colors the perception of the economic health, we present here additional analyses predicting pre-treatment economic evaluations, which are measured on a five-point scale $-1=$ the economy got much worse in the last five years, $5=$ the economy got much better. Data was taken from study 2, which asked the items of regime support, before exposing (a randomly selected group of) respondents to the economic crisis treatment. As Figure A.10 shows, both forms of support - whether instrumental or normative - significantly impact the evaluation of the economy. The higher regime support is, the more positive respondents evaluate the economy. The effects are even robust to the inclusion of the powerful effect of partisanship and apply to both government and non-government voters.

Figure A.10: Effect of regime support on economic evaluations

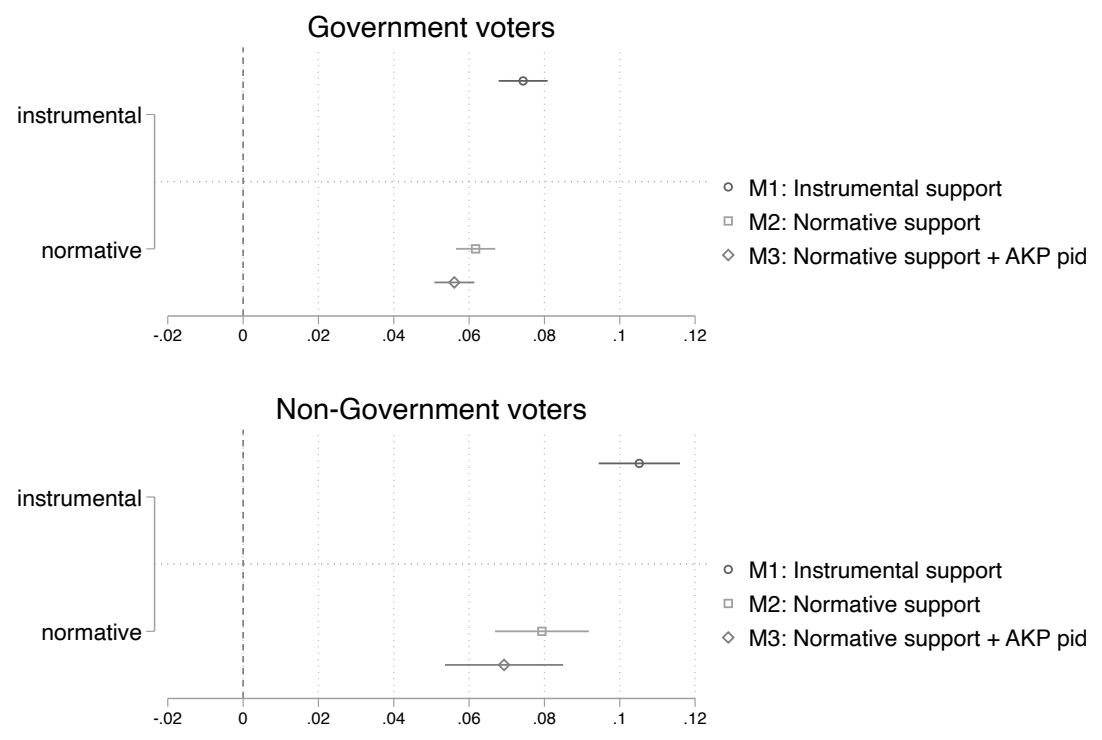

Note: The graph displays the ordered logit regression coefficient of the regime support on the pre-treatment economic evaluations using Study 2 data. The outcome Each model controls for age, gender, education, income, political interest, and urban/rural. M3 additionally controls for AKP partisanship. 


\section{Divergences to registration}

We registered our hypotheses and submitted a pre-analysis plan of this study on May 7, 2021, which can be accessed here: https://osf .io/kj8zh. When writing-up the paper, it was decided to move some of the hypotheses and analysis to the appendix, as otherwise the paper became too convoluted. In this section, we present the registered hypotheses and results of these additional analyses. The numbering of the hypotheses presented here follows the numbering as used in the registration.

The three hypotheses tested in the paper correspond to the following numbers in the registration: $\mathrm{H} 1=\mathrm{H} 3 \mathrm{a}, \mathrm{H} 2=\mathrm{H} 4, \mathrm{H} 3 \mathrm{a}=\mathrm{H} 4 \mathrm{a}, \mathrm{H} 3 \mathrm{~b}=\mathrm{H} 4 \mathrm{~b}$.

\subsection{Hypotheses on blame attribution}

We registered to test whether blame attribution mediates our economic performance treatment. The hypothesis registered is as follows:

Hypothesis 4e: Attribution of responsibility for poor economic performance, mediating the overall effect of economic performance on behavioural support for regime parties, will differ between respondents who support higher, and lower levels of normative support for the regime.

We moved these additional tests to the appendix 12 .

\subsection{Support for political objects}

We had originally planned to also distinguish the objects of support in addition to the type of support (normative versus instrumental). Here we distinguish three political objects, following Easton (1965b, 1975): the community, the regime, and the authorities. The three political objects are measured combining the following items into three indices, which range from 0 - no support to 100 complete support:

\section{Support for the community - Pride 3}

- Is it ever the case that you feel proud in your daily life because of the religion you belong to?

- Is it ever the case that you feel proud in your daily life because of your national identity and the nation you belong to?

\section{Support for the community - Regime}

- Turkey is a country that provides high quality life for its citizens.

- The Ottoman Empire period is the most glorious period in Turkish history.

\footnotetext{
${ }^{3}$ Following the results of the explorative factor analysis presented in Table A.3, we decided to treat the measures of the political community separate into two indices. The analysis showed that the two measures for national and religious pride load on different factors and should therefore be treated as separate, high-order objects.
} 


\section{Support for the regime 4}

- Approval: Strong leader who does not need to bother with the parliament;

- Approval: A political system in which only Turkish nationalist and religious parties are allowed to run in election.

- The government should have the right to ban media organizations that it thinks to be broadcasting against national interests.

- I am more satisfied with the most recent form of the political system in Turkey, compared to previous systems.

- Trust in elections

- Trust in the presidential system

- Trust in the parliament [EXCLUDED IN FINAL INDEX]

- Trust in the military [EXCLUDED IN FINAL INDEX]

- Trust in Directorate of Religious Affairs

\section{Support for authorities}

- Recep Tayyip Erdogan is a political leader with a sense of mission.

- Recep Tayyip Erdogan is an inspiring political leader.

- Job approval of Recep Tayyip Erdogan

- Job approval of Lutfi Elvan (Minister of Treasury and Finance)

- Policy evaluation: Economy

- Policy evaluation: Fight against poverty

- Policy evaluation: Internal security

Firstly, we intended to descriptively explore whether citizens express all possible types of support for the political system. We anticipated that citizens in autocracies, like citizens in democracies, will exhibit all types of support, which led to our first hypothesis:

Hypothesis 1: In authoritarian systems we observe all possible types of support.

Table 1 in the manuscript already presents the results for normative and instrumental forms of support. Table A.15 further presents the results for the three political objects. The table confirms hypothesis 1, especially for respondents who voted for the governing parties in 2018. The results confirm that support for all political objects is very high in this group. Support is much lower among opposition voters or those who abstained. The exception are the items that measure religious and national pride (which are associated with the political community), which also enjoy reasonably high support among the opposition and absentees.

Secondly, we investigate whether there are conceptual boundaries between the political objects.

\footnotetext{
4 The measures of trust in parliament and the military were excluded from the final index as an explorative factor analysis showed that these two items load on a different factor than the other items. The two institutions - parliament and the military - are less clearly linked to the regime. In contemporary Turkey, the national parliament in particular remains the main arena for the opposition parties to oppose the regime. While the relationship between the regime and the military is still strained following the attempted coup in 2016.
} 
Table A.15: Support for political objects by 2018 votes

\begin{tabular}{lcccc}
\hline & \multicolumn{4}{c}{ Vote in 2018 } \\
& All & Government & Opposition & Abstention \\
\hline Community: Pride & 70.8 & 84.3 & 55.1 & 53.2 \\
Community: Regime & 45.8 & 66.0 & 19.1 & 35.5 \\
Political regime & 44.8 & 68.5 & 14.4 & 29.7 \\
Political authorities & 44.7 & 68.7 & 13.5 & 29.8 \\
\hline N of obs & 3,820 & 1,822 & 1,548 & 410 \\
\hline
\end{tabular}

Note: The results are based on survey 2 , in which the regime support variables were asked before the introduction of the economic treatment. The results are weighted by a population weight, which was calculated based on the 2020 census data.

While research on democratic forms of support has pointed to sharp conceptual and empirical borders between the different objects of support, the political community, the regime, and the authorities, (Klingemann 1999; Klingemann and Fuchs 1995; Norris forthcoming, 1999, 2011), it is unclear whether the conceptual boundaries between the three objects Easton (1965a) identifies exist in nondemocratic settings. Indeed, in authoritarian regimes, we may observe a 'blending' of objects - with support for the community, the regime, and the authorities merged together.

There are several reasons to expect that the distinction between the different objects could be less straightforward in electoral autocracies. To begin with, leaders in authoritarian regimes often come to embody the regime and to represent its core principles (e.g. Smyth 2014). Second, a sharp distinction between the three objects may be more challenging to observe in weakly institutionalized settings, where either political parties are weak or so dominant that they become synonymous with regime institutions, such as parliaments. Finally, as Mauk (2020: 31) reminds us, the lack of constitutional constraints on the executive in non-democratic regimes and extended incumbent tenure may dampen the distinction between the different objects of support. In sum, these expectations warrant a testing of hypotheses that are sensitive to both sets of possibilities: the presence, or conversely absence of clear boundaries between the three objects of support (Easton 1965a) postulates in his general systems support framework. We formulate these expectations below:

Hypothesis 2a: Measures of support for each of the three objects, the community, the regime, and the authorities are distinguishable.

Hypothesis 2b: Measures of support for each of the three objects are not distinguishable, but blended together.

Descriptive evidence presented in Table A.3, implies that different measures of support for each of the three objects - the political community, the political regime and political authorities - are blended together. The evidence is in line with hypothesis $2 \mathrm{~b}$. 'Blending' applies in particular to the regime and the authorities, which strongly load on one latent factor.

Third, we further hypothesized the impact of the crisis treatment on the resilience of different political objects, parallel to our Hypothesis 1 discussed in the paper (which was originally H3a). We expect that support for lower-order objects is more responsive to policy outputs than support for higher order objects. Based on this we formulated H3b: 
Hypothesis 3b: Instrument, or normative forms of support for lower-order objects are more responsive to information about negative policy performance than instrumental, or normative forms of support for higher order objects.

Figure A.11 presents the results of H3b, testing the impact of the crisis treatment on support for each of the four political objects. As the figure shows the crisis treatment does not move support for any of the objects. We therefore reject H3a.

Figure A.11: Impact of crisis treatment on support for political objects: Regression coefficients and $95 \%$ confidence intervals.

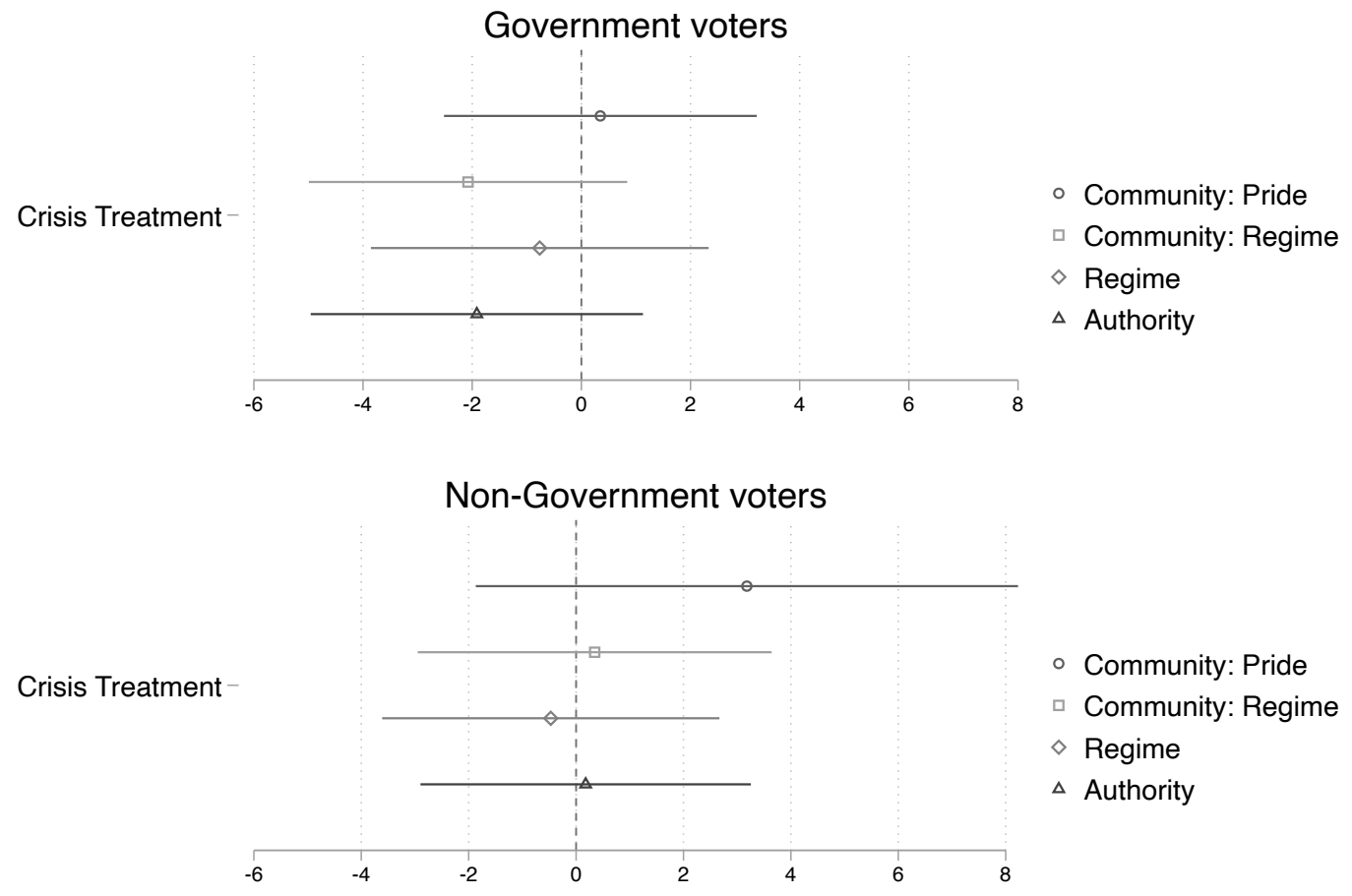

Note: The graph displays the regression coefficient of the economic crisis treatment on system support - outcome variables. Support variables range from from 0 - no support to 100 - complete support. The results are based on survey 1. The analysis are based on linear regression models with no control variables.

Fourth, we also hypothesized that the level of support for any of the political objects will moderate the impact of the crisis treatment on the behavioral electoral support for the governing parties (parallel to $\mathrm{H} 2 \mathrm{a}$ of the manuscript). The original hypothesis was formulated as follows:

Hypothesis $4 \mathbf{c}(\mathbf{H 4 c )}$ : The higher the average level of support for any of the regime objects, the less likely the impact of negative regime performance on behavioural support for regime parties.

We further also expected that the hierarchy of political objects will play a role in this conditional effect (parallel to $\mathrm{H} 2 \mathrm{~b}$ of the manuscript), leading to the next hypothesis:

Hypothesis 4d (H4d): The resilience impact $(\mathrm{H} 4 \mathrm{c})$ of support for higher-order objects is stronger than support for lower-order objects. 
Figure A.12 displays the marginal effects of the crisis treatment by the level of support for the four political objects. With the exception of the pride items measuring support for the political community, $\mathrm{H} 4 \mathrm{c}$ is confirmed. The higher support for these objects, the less the impact of the treatment on electoral support for the governing parties. However, we do not find support for $\mathrm{H} 4 \mathrm{~d}$, as the finding is the same across all objects.

Figure A.12: Interaction between economic crisis treatment and support for political objects on likelihood to vote for government parties. Marginal effects and 95\% confidence intervals. Government voters only!
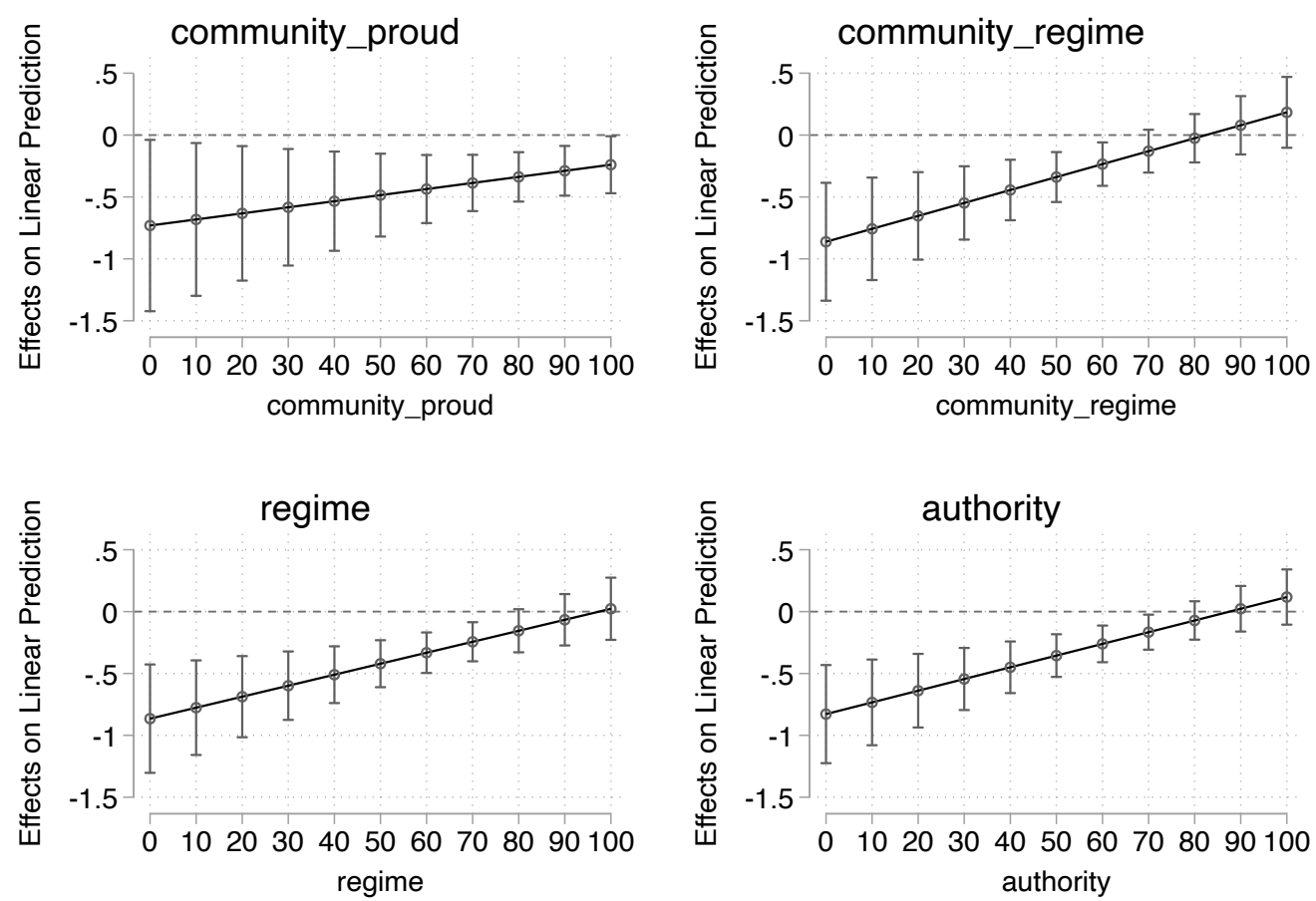

Note: The graph displays the marginal effect of the economic crisis treatment. Outcome ranges from 1 - not likely at all to 7 - very certain. The results are based on survey 2 . The analysis are based on linear regression models, controlling for income. 


\subsection{Political trust items and instrumental support}

We decided to exclude the following items from the final index on instrumental support, as these have been considered to lie between normative and instrumental support and therefore might blur the conceptual clarity of the two key concepts. The following items were included in the questionnaire that were excluded:

- Trust in elections

- Trust in the presidential system

- Trust in the parliament

- Trust in the military

- Trust in Directorate of Religious Affairs

Trust or confidence in political institution is often seen as an indicator of political system support (Norris 2011) and furthermore as a measure that that can capture popular support for both democratic and autocratic political systems (see Mauk (2020) as a recent example). However, there is a lack of theoretical and conceptual clarity in the literature on whether trust or confidence in various political institutions should be classified as normative or instrumental support (see Norris (2011) pages 63-64 for a discussion). Firstly, there is a lack of clarity about the objects of political trust, specifically the extent to which trust in particular incumbents overlaps with a sense of trust in entire institutions (Norris 2011: 64). Political trust appears to be related to both evaluations of incumbents as well as political institutions in general and in reverse (Hetherington 1998). To conclude, several studies have concluded that trust in political institutions cannot be clearly assigned to either diffuse or specific support in the Eastonian sense (Citrin and Stoker 2018: 50).

If we understand trust in terms of 'encapsulated interest' (Cook et al. 2005) - that is we trust you because you have our interests as heart - then trust relies very much on an understanding of shared interests between the trustor and trustee. In contexts where trustworthiness is inherently hard to verify, for example with regards to political institutions, citizen assessments of trustworthiness are likely to be based on affective feelings of shared interests with those in power, that is based on some in-group identities. Empirical research shows that partisanship colors trust in political institutions both in the context of democratizing regimes in Africa (Bartels and Kramon 2020) as well as in established democracies like the United States (Citrin and Stoker 2018). Norris (2011: 189) concludes the relative stability of confidence in government institutions over time would suggest that political trust is most likely the product of socialization processes and thus less reflective of fluctuations in real-time performance. We have concluded theoretically we are unable to determine whether trust in particular government institutions should be assigned to normative or instrumental support.

\section{Replicating main results using political trust}

In this section, we replicate the main results testing $\mathrm{H} 1$ and $\mathrm{H} 3$ using an index of political trust using trust in elections, the presidential system and the Directorate of Religious Affairs. We restrict the index to these three measures as the parliament and the military are less clearly associated to the Turkish regime and therefore not suitable to capture support for the regime.

As Figure A.13 shows, political trust remains unmoved by the crisis treatment. This result is similar to the one observed for normative support, while instrumental support is responsive to the crisis treatment. This could be interpreted as evidence that indeed political trust is closer to the concept of normative than instrumnetal support. 
Figure A.14 further confirms the observed conditional effect of political trust to moderate the impact of the crisis treatment on the behavioral intention to support the governing parties in an upcoming election.

Figure A.13: H1 - Impact of treatment on political trust: Regression coefficients and 95\% confidence intervals.

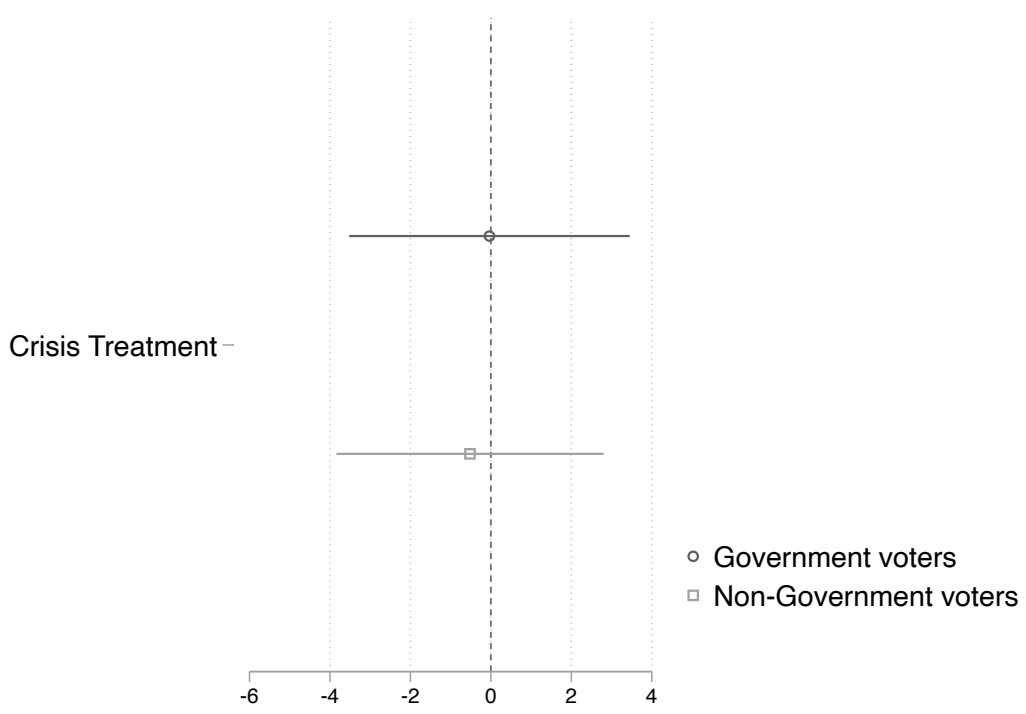

Note: The graph displays the regression coefficient of the economic crisis treatment on normative support, which ranges from from 0 - no support to 100 - complete support. The results are based on survey 1 . The analysis are based on linear regression models with no control variables. 
Figure A.14: H3: Interaction between economic crisis treatment and political trust on likelihood to vote for government parties. Marginal effects and 95\% confidence intervals. Government voters only!

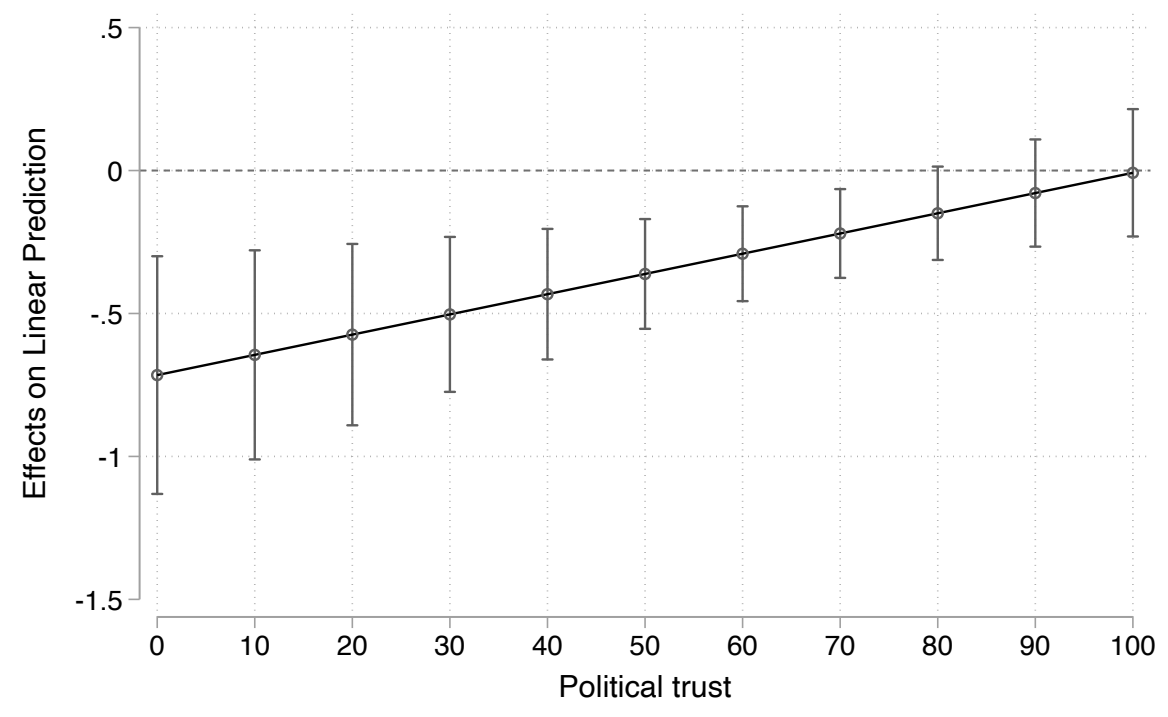

Note: The graph displays the marginal effect of the economic crisis treatment. Outcome ranges from 1 - not likely at all to 7 - very certain. The results are based on survey 2 . The analysis are based on linear regression models, controlling for income. 


\section{Distribution of variables in representative survey}

Figure A.15: Kernel density distributions for feeling thermometer scores and sociotropic economic evaluations. Sample limited to AKP voters in 2015

Distributions for AKP voters, CSES 2018
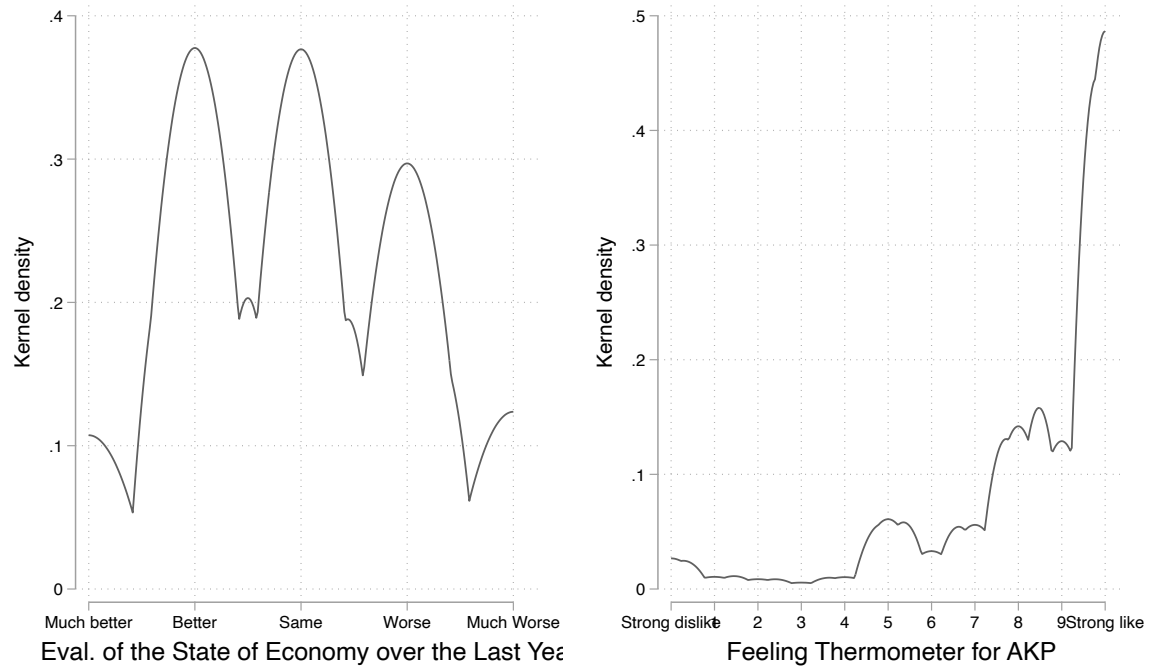

Source: CSES 2018 


\section{References}

Bartels, Brandon L and Eric Kramon. 2020. "Does public support for judicial power depend on who is in political power? Testing a theory of partisan alignment in Africa." American Political Science Review 114(1):144-163.

Booth, John A, Mitchell A Seligson, et al. 2009. The legitimacy puzzle in Latin America: Political support and democracy in eight nations. Cambridge University Press.

Citrin, Jack and Laura Stoker. 2018. "Political trust in a cynical age." Annual Review of Political Science 21:49-70.

Clifford, Scott, Geoffrey Sheagley, and Spencer Piston. 2021. "Increasing Precision without Altering Treatment Effects: Repeated Measures Designs in Survey Experiments.” American Political Science Review pages 1-18.

Cook, Karen S, Russell Hardin, and Margaret Levi. 2005. Cooperation without trust? Russell Sage Foundation.

Dalton, Russell. 1999. "Political Support in Advanced Democracies." In Critical citizens: Global support for democratic government, Norris Pippa, ed., chap. 3, Oxford: Oxford University Press.

Easton, David. 1965a. "A Framework for Political Analysis." Englewood Cliffs, HJ: Prentice-Hall .

Easton, David. 1965b. "A Systems Analysis of Political Life."

Easton, David. 1975. "A re-assessment of the concept of political support." British journal of political science 5(4):435-457.

Hetherington, Marc J. 1998. "The political relevance of political trust." American political science review 92(4):791-808.

Hicks, Raymond and Dustin Tingley. 2011. "MEDIATION: Stata module for causal mediation analysis and sensitivity analysis." Statistical Software Components S457294.

Imai, Kosuke, Luke Keele, Dustin Tingley, and Teppei Yamamoto. 2011. "Unpacking the Black Box of Causality: Learning About Causal Mechanisms from Experimental and Observational Studies." American Political Science Review 105(4):765-89.

Klingemann, Hans-Dieter. 1999. "Mapping Political Support." In Critical Citizens, Pippa Norris, ed., Oxford: Oxford University Press.

Klingemann, Hans-Dieter and Dieter Fuchs, eds. 1995. Citizen and the State. Oxford: Oxford University Press.

Mauk, Marlene. 2020. Citizen Support for Democratic and Autocratic Regimes. Oxford: Oxford University Press.

Norris, Pippa, ed. 1999. Critical Citizens: Global Support for Democratic Government. Oxford: Oxford University Press.

Norris, Pippa. 2011. Democratic Deficit. Critical Citizens Revistied. Cambridge: Cambridge University Press.

Norris, Pippa. forthcoming. In Praise of Skepticism: Trust, but Verify. New York: Oxford University Press.

Sen, Abdulkerim. 2020. "Three evils of citizenship education in Turkey: Ethno-religious nationalism, statism and neoliberalism." Critical Studies in Education pages 1-16.

Smyth, Regina. 2014. "The Putin Factor: Personalism, Protest, and Regime Stability in Russia." Politics \& Policy 42(4):567-592.

Tate, Johnisa. 2008. “Turkey's Article 301: A Legitimate Tool for Maintaining Order or a Threat to Freedom of Expression.” Ga. J. Int'l \& Comp. L. 37:181. 